\title{
Pygmy MicroRNA: Surveillance Cops in Therapy Kingdom
}

\author{
Utpal Bhadra, ${ }^{1}$ Pradipta Patra, ${ }^{1}$ Jagamohan Chhatai, ${ }^{1}$ and Manika Pal-Bhadra ${ }^{2}$
}

${ }^{1}$ Functional Genomics and Gene Silencing Group, Centre for Cellular and Molecular Biology, Uppal Road, Hyderabad, India; and ${ }^{2}$ Centre for Chemical Biology, Indian Institute of Chemical Technology, Uppal Road, Hyderabad, India

\begin{abstract}
MicroRNAs (miRNAs) are well preserved in every animal. These pygmy-sized (21-23 nt) noncoding RNAs scattered in the genome are responsible for micromanaging versatile gene regulation. There is involvement of miRNAs as surveillance cops in all human diseases including cardiovascular defects, tumor formation, reproductive pathways, and neurological and autoimmune disorders. The effective functional role of miRNA can be reduced by chemical entities of antisense oligonucleotides and versatile small molecules that support the views of novel therapies of different human diseases. In this study, we have updated our current understanding of designing and synthesizing miRNA-controlled therapeutic chemicals. We have also proposed various in vivo delivery strategies and discuss their ongoing challenges to combat incorporation hurdles in live cells and animals. Lastly, we have demonstrated the current progress of miRNA modulation in the treatment of human diseases to provide an alternative approach to gene therapy.
\end{abstract}

Online address: http://www.molmed.org

doi: $10.2119 / \mathrm{molmed} .2016 .00136$

\section{INTRODUCTION}

Structurally, miRNAs are around 21-23 nucleotides (nt) long and they function by directing Argonaute proteins to bind with mRNA targets with complementarity to repress their expression $(1,2)$. To date, several miRNAs have been discovered that are involved in the cellular processes, development, and suppression of target genes. Inappropriate expression of miRNAs is associated with diseases like cancer, diabetes, cardiac diseases, tissue-specific neurodegenerative disorders, and other physiological problems. For example, let-7 miRNA inhibits cancer stem cell proliferation (3). Dysregulation of $m i R-103$ and $m i R-208$ leads to diabetes and obesity, whereas $m i R-375$ regulates insulin hormone secretion (4). Mutation in $m i R-96$ is associated with hearing loss. A very different mutation in miR-96 was discovered in a mouse mutant with hair cell defects and progressive loss of hearing (5). Hepatitis $C$ virus replicates by the regulation of miR-122 activity (6). Several viruses express their own miRNAs to suppress their cellular mRNAs. New strategies have been developed to use miRNA in gene therapy. Limitations such as hybridization-related off-target effects and issues regarding delivery are still in the resolving pipeline to achieve the desired approach. Thus, specific molecules related to inappropriate function and association of specific abundant miRNAs provide new strategies in diagnostic and therapeutic approaches.

\section{THE microRNA SILENCING MACHINERY IN ANIMALS}

\section{Biogenesis of microRNAs}

Transcription of miRNA genes follows a similar hallmark as protein-coding

Address correspondence to Utpal Bhadra, Centre for Cellular and Molecular Biology, Uppal Road, Hyderabad-500007, India. Phone: 91-40-27192513; Fax: 91-40-27150591; E-mail: utpal@ccmb.res.in Submitted May 25, 2016; Accepted for Publication September 13, 2016; Published Online (www.molmed.org) September 28, 2016.

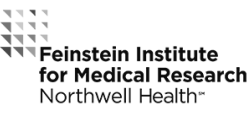

genes. Canonical miRNA genes are transcribed by RNA polymerase II into a 250-300 nt precursor called pri-miRNA, which contains one or more imperfect hairpin loops approximately $32 \mathrm{nt}$ in length (7). Pri-miRNAs are 5' capped and have a polyadenylated tail. The miRNAs are processed in two steps (8), the first occurring in the nucleus and the second in the cytoplasm. The pri-miRNA undergoes the first nucleolytic processing step by the concerted action of DGCR8 (in humans)/PASHA (in fruit flies), a protein containing the double-stranded RNA binding domain (dsRBD) and DROSHA, an RNase III family protein. DGCR8/PASHA directs DROSHA to cleave the pri-miRNA at the base of the hairpin stem, resulting in a 70 nt pre-miRNA hairpin with multiple bulges, mismatches, and the characteristic RNase III enzyme cleavage signature of a $5^{\prime}$ phosphate, $3^{\prime}$ hydroxyl, and $2 \mathrm{nt}$ $3^{\prime}$ overhang (9). The $2 \mathrm{nt} 3^{\prime}$ overhang is specifically recognized by the nuclear export protein EXPORTIN 5, which exports the pre-miRNA from the nucleus to the cytoplasm in a Ran-GTP-dependent manner (10). In the cytoplasm, the premiRNA undergoes a second nucleolytic cleavage step mediated by an RNase III family protein, Dicer 1 (11) (Figure 1). 


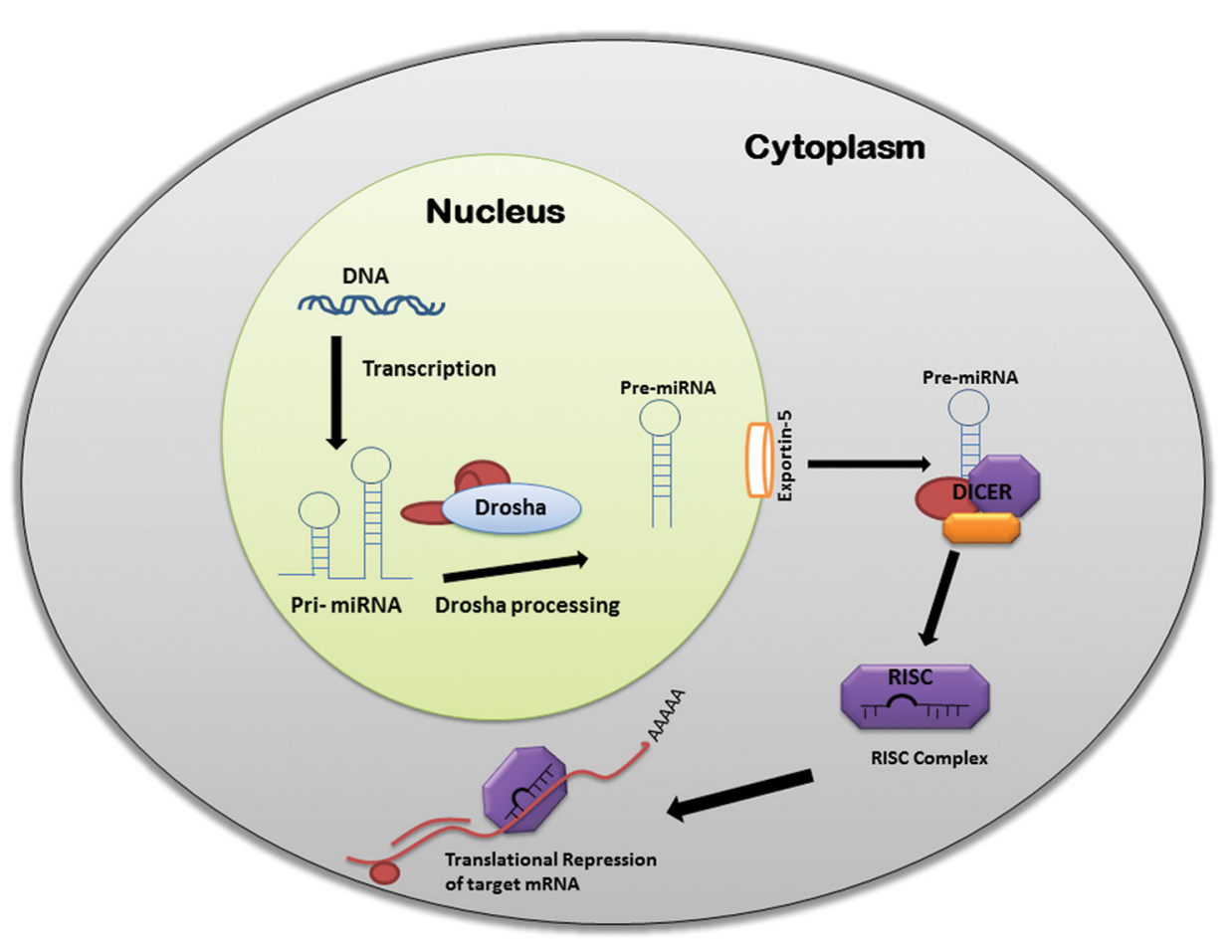

Figure 1. Simplified diagram of general miRNA biogenesis. Complementary DNA of pri-miRNA synthesize hairpin structure Pre miRNA that carries 5' Cap and 3' poly A tail. Drosha and DGCR8 of dsRNA-binding protein complex cleaves nearly 55-70 nt long Precursor miRNA (pre-miRNA) and it is exported from nucleus to cytoplasm using Exportin 5 enzymes. Pri miRNA together with Dicer and TAR RNA binding protein (TRBR) or PACT remove the loop and produce miRNA duplex from precursor RNA. MiRNA duplex is loaded to RISC complex and synthesized the mature miRNA for translation repression and transcriptional degradation.

Humans have a single Dicer enzyme that functions in both short interfering RNA (siRNA) and miRNA pathways, while Drosophila has two Dicer enzymes (2). The siRNA consists of 21 nucleotides with $5^{\prime}$ overhangs for interference at the translation level to prevent the synthesis of specific proteins on the basis of nucleotide sequences of their complementary mRNA. Drosophila Dicer 1 functions in the miRNA pathway in the cytoplasm, and Dicer 2 functions in the siRNA pathway in the nucleus, while C. elegans has a single Dicer enzyme (12). During the nucleolytic cleavage step, Dicer 1 is assisted by TRBP (humans)/PACT (humans)/Loquacious (Drosophila), which are dsRBD-containing proteins (dsRBP) (13). Drosophila Dicer 2 is assisted by R2D2 (a dsRBP) for processing of long dsRNA and shRNA (short hairpin RNA) substrates into siRNAs (14). The cleavage of pre-miRNA by Dicer 1-TRBP/PACT/ LOQS occurs about two helical turns from the base of the stem and yields about 22 nt long miRNA/miRNA* duplex with characteristic 2 nt $3^{\prime}$ overhangs in both strands (15). The miRNA strand accumulates to a greater level compared with the miRNA* partner. The well-conserved miRNA* may have some regulatory functions and distinct Argonaute sorting properties (16). Relative thermodynamic instability of the miRNA/miRNA* duplex dictates which strand will be preferentially loaded in the miRNA induced silencing complex (miRISC) or miRibo nucleoprotein complex (miRNP). The duplex is most likely unwound by DEAD box helicase proteins GEMIN3 (humans) / ARMITAGE (Drosophila) $(17,18)$.
The mmu-miR-451 forms a subclass of miRNAs that have a unique feature compared with canonical miRNAs that map to the stem region of pri-miRNA (19). DROSHA processes this mmupri-miR-451 to 41 nt mmu-pre-miR-451 (in contrast to normally $\sim 70 \mathrm{nt}$ long pre-miRNAs) $(20,21)$. This mmupre-miR-451 does not undergo a second Dicer1 dependent processing step in the cytoplasm; rather it is directly loaded into miRISC, where it is further processed into its mature form by the action of AGO2 (in mouse) $(22,23)$.

\section{Regulation of microRNA Gene Transcription}

Early experimental data suggested that expression of several miRNA genes was regulated temporally and spatially $(24,25)$. A process similar to proteincoding genes controls transcription of canonical miRNA genes. Promoters of miRNA genes also have characteristic features such as TATA box, CpG islands, enhancers, initiation elements, and transcription factor (TF) binding sequences (26). TFs regulate transcription of specific miRNAs in a tissue-specific or developmental stage-specific manner. Autoregulatory feedback loops are a common method for controlling the expression of protein-coding genes. Similar strategies are also found in the regulation of miRNA genes, as some of these genes are known to regulate TFs negatively, which are required for their own expression in an autoinhibitory fashion. For instance, $m i R-133 b$ regulates the maturation and function of dopaminergic neurons in the mammalian midbrain using a negative feedback circuit with the transcription factor PITX3. PITX3 induces transcription of $m i R-133 \mathrm{~b}$, while $m i R-133 \mathrm{~b}$ negatively regulates PITX3 $(27,28)$.

\section{Gene Regulation by microRNAs}

Post maturation, miRNAs are required to be integrated with miRISC, a large multiprotein complex that carries out sequence-specific mRNA silencing activity. The most important catalytic component of miRISC is an Argonaute (AGO) family 
protein. The AGO proteins have a central PAZ (PIWI, Argonaute, and Zwille) domain and a C-terminal PIWI domain. The PAZ domain binds to the $3^{\prime}$ end of miRNA, while the PIWI domain binds the 5' end. The DDH motif in the PIWI domain resembles the DDE motif of RNase $\mathrm{H}$, a nuclease that catalyzes cleavage of RNA-DNA hybrids $(29,30)$.

The majority of animal miRNAs bind their target mRNAs with imperfect complementarities in the 3' UTR region of mRNA and usually lead to translation repression, without affecting the levels of target mRNA (31). Experiments on let-7 miRNA show that initiation of capdependent translation of target mRNA is repressed, while cap-independent translation initiation (as in the case of internal ribosome entry site) or artificially through tethered eukaryotic initiation factor $4 \mathrm{E}$ and $4 \mathrm{G}$ (eIF4E and eIF4G) is not affected.

Cap of target mRNA by the eIF4E represses the initiation of translation. Artificial tethering of human AGO protein on the target mRNA leads to repression of translation, even in the absence of miRNA (Figure 2) (32). Similar findings were obtained by tethering AGO1 protein on the reporter RNAs in Drosophila (33), suggesting that the only function of miRNA is to target sequence-specific miRNA silencing complexes to target mRNA. Immunoassaying has revealed that all human AGO proteins concentrate in discrete foci that colocalize with cytoplasmic processing bodies or $\mathrm{P}$ bodies (PBs) (34). PBs are sites for degradation/ turnover of eukaryotic mRNAs (35). Decapping enzymes DCP1/2, 5'-3' exonuclease XRN1 and GW182 proteins are localized in PBs (also called GW bodies because of the presence of GW182 protein) (36) AGO proteins have been shown to physically interact with $\mathrm{P}$ body components. Interestingly, miRNAs and their target mRNAs have been shown to be present in PBs (37). Mammalian GW182 protein has been shown to bind miRNAs and sequester target mRNAs, thus contributing to its posttranscriptional regulation $(2,38)$. Knockdown of GW182

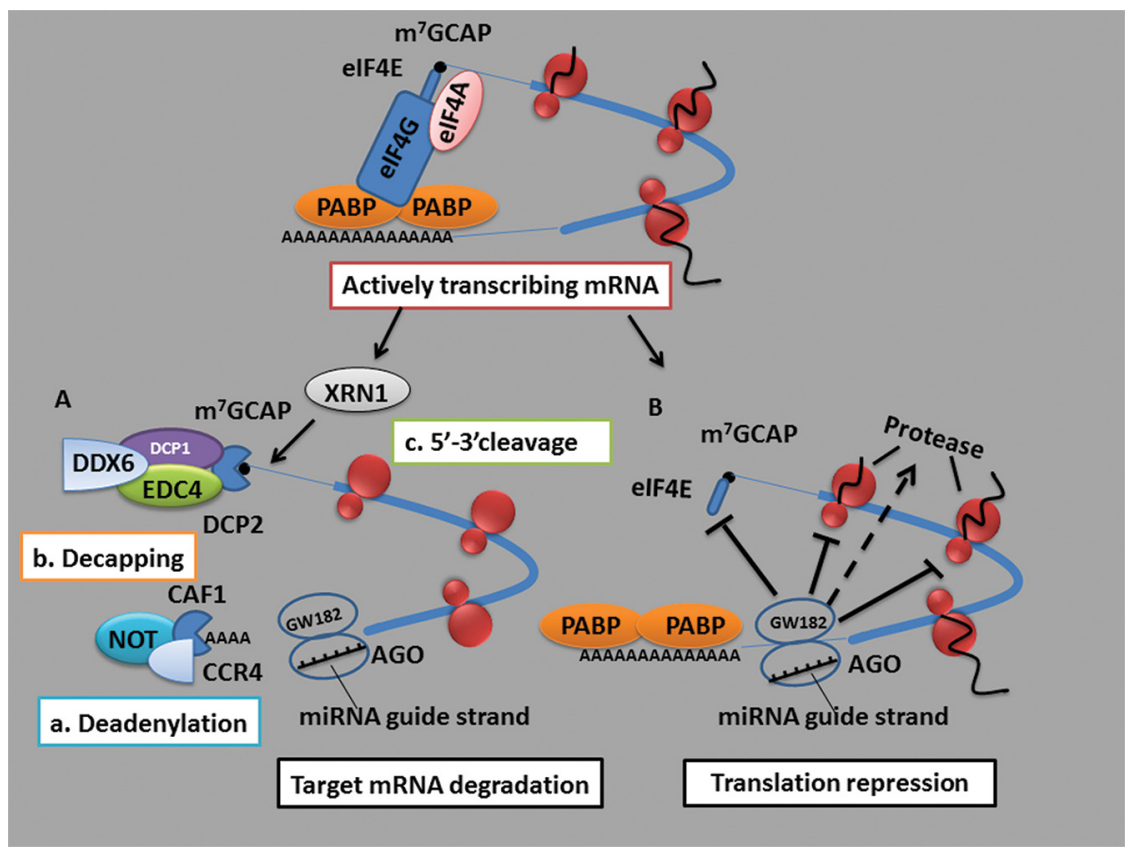

Figure 2. Process for miRNA-mediated gene regulation. The mechanism of two types of microRNA-mediated gene regulation are shown: (A) targeted mRNA degradation: Decapped mRNAs are targeted by XRN1 (cytoplasm) that leads to degradation of mRNA. miRNA mediated mechanism affects the stability of mRNA and causes removal of the ends of mature mRNA in the cytoplasm and targeted mRNA is degraded (B) translation inhibition. Figure reproduced with permission of Frontiers Research Foundation. Sethi A, Kulkarni N, Sonar S, Lal G. (2013) Role of miRNAs in CD4 T cell plasticity during inflammation and tolerance. Front. Genet. 4:8 (cited as reference (39) in the current review).

in Drosophila S2 cells leads to dispersed miRNA-mediated silencing, which confirms its role in miRNA function (40). Translation inhibition by AGO2-RISC is independent of GW182 and is thought to work by a mechanism distinct from the AGO1-containing RISC (41). Functional consequences of such miRNA sorting in AGO1- and AGO2-containing RISC complexes are yet to be discovered. The mechanism for miRNA gene transcription is summarized in Figure 3.

\section{Modalities of Therapeutic microRNAs}

Currently, there are two main approaches to miRNA-based therapy, miRNA mimics and miRNA antagonists, which are associated with loss of function and gain of function of the diseased tissue, respectively. Loss of function of diseased tissue can easily be restored by miRNA mimics, which are generally known as miRNA replacement therapy (42). In this case, reintroduction of miRNA leads to reactivation of several interrelated pathways, which are essentially required for normal cellular behavior and inhibit those disease-inducing steps. miRNA replacement therapy includes a tumor suppressor, which inhibits oncogenic pathways and promotes normal growth control mechanism apoptosis and tumor eradication (43). The specific delivery of miRNA mimics to tumors is challenging, therefore systematic miRNA is the only possible strategy that can be selectively used in siRNA therapeutics (44). On the other hand, the positive aspect of miRNA mimics is their high specificity. Based on recent studies, it is expected that administration of miRNA mimics to normal tissue is not likely to induce adverse effects, as the mimicsmediated affected cellular pathways are already activated or inactivated by endogenous miRNA $(45,46)$. 


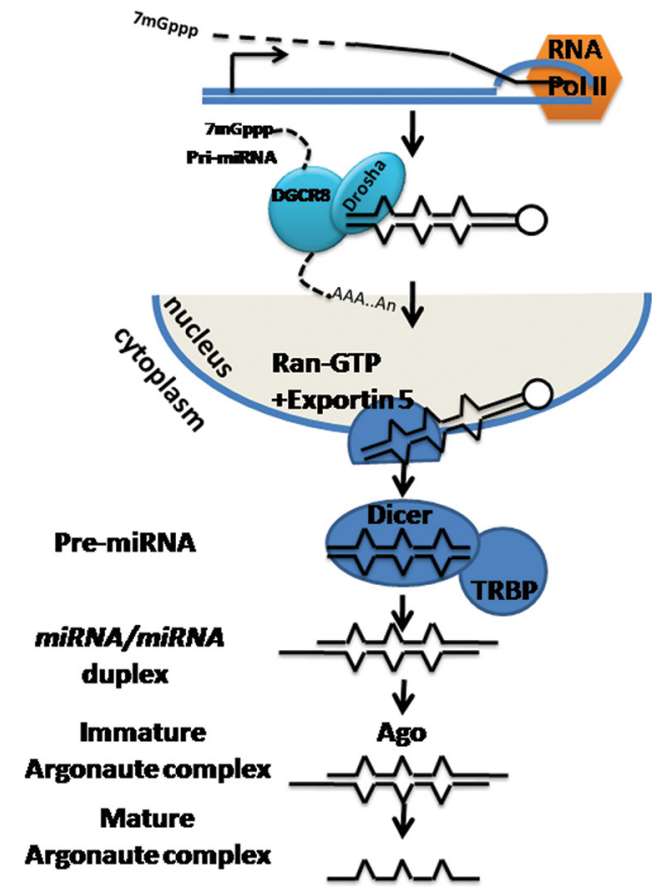

Figure 3. Argonaute proteins in the RISC-miRNA complex helps in conversion of precursor miRNA to mature miRNA. Abbreviations: AGO, Argonaute; GTP, guanidine 5' triphosphate; Pol II, polymerase II; TRBP, transactivation-response-RNA binding protein. In the cytoplasm, the miRNA duplex is associated with Argonaute proteins of the RISC-miRNA complex. One of the strands of miRNA duplex, referred to as a guide strand, is retained in the AGO to form miRNA-induced silencing. Figure reproduced with permission of Elsevier. Matranga $C$, Zamore PD. (2007) Small silencing RNAs. Curr. Biol. 17:R789-R793. (cited as reference (47) in the current review).

MicroRNA antagonists generally inhibit endogenous miRNAs, which show gain of function in affected tissues. This goes along with other inhibitory therapeutic approaches that mainly target short interfering RNAs and small inhibitory molecules. In this process, a highly chemically modified miRNA passenger strand interacts with the active miRNA strand with high affinity. The nascent miRNA duplex cannot be degraded or modified by RISC due to the irreversible machinery of miRNA antagonists (Figure 4) $(48,49)$.

\section{THERAPEUTIC FUNCTIONS OF ANIMAL MICRORNAS}

\section{MicroRNAs in Cancer and Cancer Stem Cells}

Currently, the association of miRNAs with cancer has been well reported. Epigenetic regulations mainly lead to improper expression of miRNA genes. Aberrant expression of numerous miRNAs in tumor cells leads to erroneous regulation of their specific target mRNAs. Some oncogenic miRNAs are $m i R-10 \mathrm{~b}, m i R-155, m i R-21$, and $m i R-$ 17-92, whereas miRNAs such as miR-26a, miR-126, miR-335, and members of let- 7 and $m i R-34$ are considered tumorsuppressor miRNAs $(50,51)$. Evidence shows that miR-10b plays a role in metastasis, whereas inhibition of $m i R-10 \mathrm{~b}$ arrests cancer cell metastasis (52). miR-335 inhibits metastases but fails to regulate proliferation and apoptosis of tumor cells $(52,53)$. miRNAs can regulate several oncogenes involved in different oncogenic pathways. As an example, miR-34a can repress several proto-oncogenes, such as $c-$ Met (hepatocyte growth factor receptor) and cyclin-dependent kinase 4 (promotes progression of cell cycle) and
BCL2 (B cell lymphoma 2, oncogenic protein), which block apoptosis $(54,55)$.

Overexpression of miRNAs with "oncogenic" potential, such as miR-17-92, accelerates $C$-myc-induced tumor genesis by suppressing pro-apoptotic factor E2F1 (56). miR-372 and miR-373 target tumor suppressor LATS2 (large tumor suppressor kinase 2) and induce tumorigenesis. These miRNAs are expressed specifically in testicular germ cell tumors. Overexpression of other miRNAs such as miR-155 is associated with B cell lymphomas $(57,58)$.

miRNA also plays a significant role in cancer stem cells, which are defined as the seed of the tumor, with tumorigenicity and metastatic behavior, and are refractory to therapy (59). Cancer stem cells possess differentially expressed miRNA, which regulates their phenotypic characteristics. As an example, let-7 and $m i R-34$ are downregulated in cancer cells and at very low levels in cancer stem cells $(60,61)$. It has been shown by functional assay that let-7 and miR-34 interfere with cancer stem cell phenotypes in vitro and in vivo (62).

\section{Cancer Therapies and Targeting Tumor Microenvironment}

Another potential target for miRNA-based therapy is the tumor microenvironment. Onco-miRs are involved in the onset and maintenance of cancer when upregulated. This dependence is classically termed as onco-miR addiction. In effective anticancer therapy, oncogenes like EGFR and HER2 are targeted often. Therefore, inhibition of onco-miRNAs by anti-miRNAs (antisense oligomer) provides a novel effective strategy in therapeutics $(63,64)$.

Besides, cancer is not limited to malignant epithelial components, but different stromal cells such as fibroblasts, inflammatory cells, and endothelial cells form a specialized microenvironment (TME) to promote tumor formation, progression, and metastasis to other organs.

Researchers have shown that an acidic tumor microenvironment can be targeted by a construct of peptide nucleic acid anti-miRNAs and a low $\mathrm{pH}$-induced 


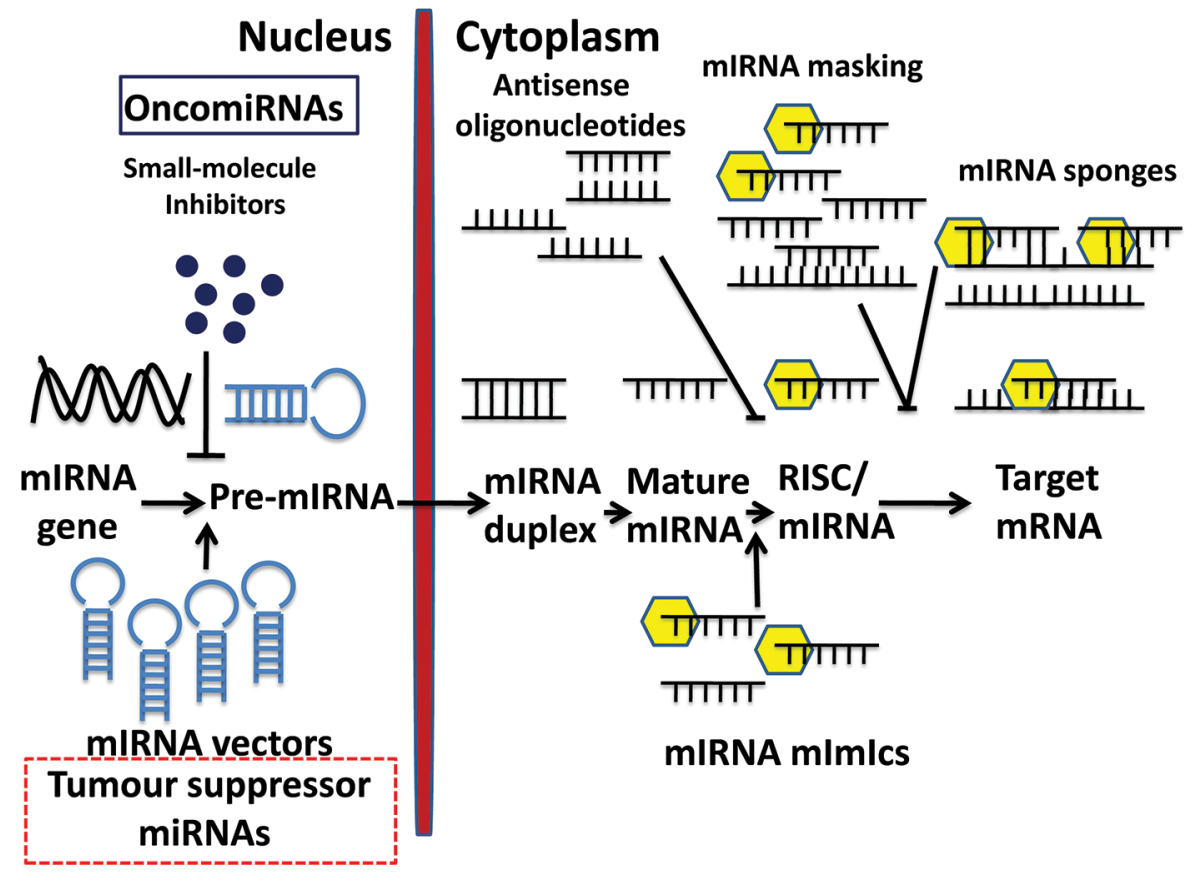

Figure 4. The implication and function of oligos or virus-based constructs can either hinder onco-miRNA expression or induce loss of expression of tumor-suppressor miRNA. A novel approach is using drug to alter miRNA expression by modulating their transcription and processing. Figure reproduced with permission of Elsevier. Fassan M, Baffa R. (2013) MicroRNAs and targeted therapy: small molecules of unlimited potentials. Curr. Opin. Genet. \& Dev. 23:75-7. (cited as reference (65) in the current review).

transmembrane structured peptide (pHLIP) to deliver anti-miRNA. It facilitates entry into the cell through a nonendocytic pathway. This novel model of anti-miRNAs as an anticancer agent has a broad impact in targeted drug delivery (66).

For initiation of tumor growth, angiogenesis, invasion, and metastasis, communication between stromal cells and tumor cells is very important. Stromal cells in the tumor microenvironment include tumor-associated fibroblasts, onco-macrophages, endothelial cells, pericytes, and infiltrating immune cells. MicroRNAs in the tumor microenvironment have myriad roles in tumor development and progression. Interestingly, miRNAs are dysregulated in different stromal cells, and they have a major impact on the regulation of intercellular crosstalk in the tumor microenvironment. Since miRNA delivery is quite challenging and the biggest hurdle for clinical researchers have been exploring various nonviral miRNA delivery systems that can potentially be used for targeting miRNA to stromal cells within the tumor microenvironment (67).

Despite this progress, there are still enormous challenges, particularly in how to select the optimal cancer patients and how to establish the optimal treatment schemes. Therefore, well-established biomarker candidates and detection techniques need be developed along with therapeutic strategies targeting CAFs and the other components in TME.

Researchers have shown that intense suppression of the immune system exist in the glioblastoma-associated microenvironment. This leads to invasion and progression of glioma and systemic inhibition of antitumor immunity. The role of microRNAs (miRNAs), discussed already, is that they modulate tumor cell proliferation and apoptosis and subsequently translation of miRNA therapeutics, function as oncogenes or tumor-suppressor genes. Ongoing research has shown that $m i R-142-3 p$ is a useful biomarker and potential therapeutic target in a variety of malignancies (68-71).

Earlier studies on miR-142-3p mainly focused on either expression frequency or prognostic impact; emerging data indicates involvement of $m i R-142-3 p$ in immunological reactivity and activation (72-74), including immune suppression of T cells (75-79). On the other hand, miR142-3p may influence the differentiation process of immune cell populations. Glioblastomas potentially recruit circulating macrophages to tumor-associated areas and induce acclimatization to a tumor-supportive M2 phenotype, which can mediate suppression of immune expression and progression of invasion.

\section{Let 7 and Bantam microRNA in Cancer}

Let-7 is the one of the primitively discovered miRNA genes that regulates the development of C. elegans (80). After earlier experiments (81), it was proposed that let-7-mediated inhibition of RAS leads to shorter survival of lung cancer patients (82). Reduced expression of let-7 was observed, which leads to upregulation of high mobility group AT-hook protein 2. This increases anchorage-independent growth of the cell and oncogenesis (83). Let-7-induced growth inhibition was also reported in multiple cell lines with KRA-associated mutation and suppression of tumor growth in a human lung cancer xenograft model (84). The miRNA therapeutics companies (MiRNA Therapeutics, Benitech, Biopharma, Arbutus Biopahrma) are struggling to develop let-7 as a potential miRNA replacement therapy for cancer treatment (85). It would be a grand success if miRNA mimetic delivery were to have a potential therapeutic impact on anticancer treatment.

The bantam, a 21-nucleotide gene in Drosophila, is a potential miRNA or proto-oncogene that actively promotes cell proliferation, death, and other developmental patterns. Patterning cues 
regulate temporal and spatial bantam expression. It has been shown that bantam miRNA induces cell proliferation and inhibits apoptosis simultaneously. Scientists have identified hid as a pro-apoptotic gene, which can be an effective target for regulation by the bantam miRNA. Researchers have reported that histone deacetylase inhibitor can regulate bantam miRNA expression, however HDAC inhibitor can promote the hid-induced apoptosis machinery $(86,87)$. Experimental data support that the mitochondrial regulatory pathway in human cancer cell lines can be affected by HDAC inhibitor, which suggests a conservative feature of apoptosis between Drosophila and humans. Targeting hid supports the explanation for bantam's negative regulation in apoptosis.

\section{microRNA in Neurological Disorders}

As delivery of oligonucleotide targets through the blood-brain barrier is very selective, miRNA therapeutic strategies for neurological disease are extremely challenging. Advanced research has shown that miRNAs are actively involved in the regeneration, regulation, and function of the central nervous system $(88,89)$. Studies in C. elegans and cultured cell systems have shown that several distinct miRNAs are actively linked to neurodegenerative diseases, such as Parkinson's and Alzheimer's disease (90). Experimental data from AD patients' brains has shown downregulation of $m i R 29 \mathrm{ab}-1$ and $m i R$ $107(91,92)$. On the other hand, it has been predicted that miR-298 and miR-328 may be involved in modulation of amyloid precursor protein (APP) converting enzyme, which ultimately leads to Alzheimer's through APP processing $(93,94)$. A validated set of miRNAs has not yet been identified in AD-damaged regions, so the full impact of miRNAs in AD is still to be explored (95). Along with the several up and down regulations of selective miRNAs, an interesting link has been discovered with mutation of the LRRK2 (leucine-rich repeat kinase 2) gene, which is a familiar to cause Parkinson's disease. It has been suggested that the association of LRRK2 with human Argonaute-2
(hAgo2) may lead to misregulation of many miRs $(59,61,96)$. This is also associated with other neurodegenerative diseases such as Huntington's disease, ataxia, epilepsy, traumatic injury (97), Tourette's syndrome, neuropsychiatric diseases such as schizophrenia, and amyotrophic lateral sclerosis (ALS) (98-100).

\section{microRNA in Cardiac Diseases and Heart Regeneration}

The miRNAs miR-208 and miR-195 (miR-15 family) are highly expressed in heart and cardiac ventricles (during postnatal switch), and miR-208 is encoded in the intronic region in mouse $\alpha$-myosin heavy chain genes $(101,102)$. According to experimental evidence miR-208 knockout mice developed normally but when induced with pressure-overload-stress, gradual loss of cardiac function and failure of cardiac hypertrophic growth initiation were observed (85). Researchers have shown that miR-208 inhibition by a locked nucleic acid (LNA) modified anti-miR could potentially protect rats from induced heart failure and hypertension (103). Currently, dose-dependent experiments are at the preclinical stage, to reduce cardiac toxicity (104-105).

miR-195 is widely expressed during the neonatal stage of cardiac regeneration. Overexpression of $m i R-195$ in the embryonic heart potentially leads to ventricular hyperplasia and septal faults (106). Experimental evidence has shown that several cell cycle genes along with checkpoint kinase1-targeted cardiomyocyte proliferation can occur by regulation of miR-195 (107). Interestingly, miR-195 inhibition by LNA-modified anti-miRs in pigs and mice showed steady effects on heart regeneration, whereas treated animals were devoid of myocardial infarction (108). Currently, therapeutics associated with miR-195 targets are at the preclinical stage (109).

\section{microRNA in Insulin Sensitivity and Diabetes}

Like $m i R-208, m i R-103$ and $m i R-107$ are encoded within the intronic regions of pantothenic acid kinases. Overexpression of these miRNAs results in deregulated glucose homeostasis, whereas inhibition shows improved glucose homeostasis and insulin sensitivity in leptin-deficient and diet-induced obese mice (110). Experimental data proved that $m i R-103$ and miR-107 can directly target voltage-gated calcium channel Cav1, which acts as the crucial insulin receptor regulator (111). Therefore, these miRNAs can be an efficient target for obesity-associated insulin resistance. Most of the miRNA target molecules are at the preclinical stage.

\section{Pathogenic Virus and microRNAs: A Complex Relation}

Viruses possess an intracellular replication cycle and use miRNAs for infection, replication, and survival in the host system. Various ways of interfering with virus and host-system miRNA have been reported to date, and it has been observed that viruses drastically manipulate host-cell miRNA expression or produce their own miRNA to regulate infection and pathogenesis. Researchers have shown HIV and HCV as examples of this interplay, showing how fine-tuned miRNA expression is vital for regulating key host pathways that mediate infection and replication of virus, host immune bypass, and survival in the niche, which dictates the fate of the pathogen and host cell $(112,113)$.

miRNAs are also involved in interactions with pathogenic viruses. Virally encoded miRNAs interfere with normal cellular physiology such that a virus can continue its life cycle. miR-S1, a miRNA encoded by simian vacuolating virus 40 (SV40), helps to keep the infected cells hidden from the immune system by targeting early viral mRNA-encoding T antigen for degradation $(114,115)$. Herpes simplex virus 1 (HSV1)-encoded miRNA, miR-LAT, targets pro-apoptotic transforming growth factor $\beta$ (TGF $\beta$ ) and SMAD3, thereby inhibiting apoptosis of latently infected neurons $(116,117)$. Host cells also use miRNA to regulate replication of viruses; for example, host cell-encoded miR-32 inhibits replication 
of primate foamy virus type 1 (PFV1), while PFV1 encodes a protein, Tas, that suppresses miRNA-directed functions in mammalian cells and displays crosskingdom antisilencing activities $(118,119)$. There are examples where the virus exploits host miRNAs for its own advantage. For instance, $m i R-122$ is required for efficient replication of $\mathrm{HCV}$, but it affects neither translation or stability of HCV RNA. It is believed that miR-122 binding may provide a structural feature required for replication, or it may help in recruitment of protein factors required for replication (120).

\section{Viral microRNA-Mediated Response in Therapeutics}

It has been shown that at least 66 distinct miRNAs are produced by mammalian viruses (121). miRNA-producing viruses mainly belong to the herpes virus family (dsDNA), whereas other double-stranded DNA viruses such as papilloma virus and flavovirus, and RNA viruses such as retrovirus are restricted from producing miRNA (121). Viral miRNAs curb the host immune response during infection by altering major histocompatibility complex class I chain-related molecule B (MICB) expression. miRNA expressed by pathogenic viruses, such as herpes virus associated with Kaposi's sarcoma virus, Epstein-Barr virus, and human cytomegalovirus, target specific catalytic sites in MICB mRNA and inhibit its expression $(92,121)$. Researchers have shown that human cytomegalovirus expresses miR-UL112, which targets the $3^{\prime}$ untranslated region of MICB. This virus overlaps the binding site of cellular miRNA, miR-373 $(122,123)$. Due to the presence of adjacent sites for miR-433a and miR-367a in MICB mRNA, interaction between viral miR-UL112 and cellular miR-376a is feasible, which leads to silencing of MICB expression in a human cytomegalovirus-infected person $(124,125)$. It has also been shown that expression of two miRNAs, miR-429 and miR200b, regulates entry to the lytic phase of Epstein-Barr virus by suppressing expression of ZEB1 and ZEB2. Therefore,
miRNA inhibitors may be used to persuade latent viruses into a tractable state of active replication, which can be a novel strategy in antiviral therapeutics $(126,127)$.

\section{Reintroduction of Missing microRNA: A Therapeutic Approach}

Loss or reduced expression of particular miRNA leads to several diseases, such as cancer. It has been proven that let-7 miRNA has the potential to suppress oncogenes such as Myc, Ras, and HMGA-2. Significantly low levels of let-7 and high HGGA-2 mRNA expression in tumors were found in 100 diagnosed ovarian cancer patients $(83,128)$. Interestingly, it has been found that let-7 expression in cancer stem cell is lower than normal mamosphere cell, indicating that let-7 may inhibit proliferation of cancer-inducing stem cells (129). In B cell lymphocytic leukemia, deletion of miR-15 and miR-16 is observed often, whereas in prostate cancer, miRNA expression reduces by $80 \%$. Thus, several miRNAs possess the classical features of tumor-suppressor genes. Substitution of these tumor suppressor miRNAs can be a potential approach in tumor chemotherapy (130).

In many cases, missing miRNAs can easily be replenished by reintroducing new miRNAs. Multiple doses of siRNA are required due to their inefficient delivery, lower incorporation rate, and degradation. On the other hand, several viral vectors encoding short hairpin RNAs can infect cells, which ultimately supply mature miRNAs. Thus, miRNA expression can easily be optimized in a cell through delivery with a viral vector. Researchers have shown that Argonaute proteins and short hairpin RNA exporting proteins such as exportin- 5 are able to limit the yield of total exogenous miRNA $(131,132)$.

\section{microRNA-Mediated Gene Therapy Improvement}

Defective genes in several genetic diseases can be replaced by traditional gene therapy with a great efficacy. Due to a leaky promoter, it is challenging to obtain the proper expression of the therapeutic transgene. miRNA association in gene therapy can promote the potent expression of transgene. As an example, delivered transgene with the binding site for $m i R-122$ can be easily silenced in hepatocytes because it has specificity for liver tissues (133). This strategy has been widely used to restrict transgene expression through a lentiviral vector in astroglial cells $(134,135)$. In the mouse hippocampus, injection of engineered lentiviral vector with inserted $m i R-124$ target site to 3' UTR produces transgene expression in astrocytes and Bergmann glial cells, but not in Purkinje cells or pyramidal neurons $(134,136)$.

Researchers have reported that detargeting of transgene by miRNAs is also possible, which leads to enhancement of immune tolerance of an antigen coded by transgene. On the other hand, it has also been shown that a genetically engineered adenovirus, replicationselective oncolytic virus, can infect cancer cells selectively. The specificity of the miRNA-associated engineered virus makes it useful as a potent alternative to chemotherapy (137).

In stem cell therapy, removal of the pluripotent cell population is a critical process. To restrict unwanted cell proliferation and tumor formation, it is necessary to remove the stem cell population before transplanting back to the native cell population (138). Differentiated pluripotent stem cell-specific miRNA can regulate suicide gene expression and fluorescent gene expression. Cell type-specific miRNA can block suicide gene expression to allow the lineage-specific differentiated cell to proliferate, whereas reporter gene can be turned off by miRNA to permit separation between differentiated cell and pluripotent cell (121). Transgene expression can be repressed in several cells or tissue types by a combination of multiple miRNA target sites. This advanced strategy can be used to achieve the desired level of transgene expression by accurately aligning miRNA expression and enhancing target site affinity (139). 


\section{microRNA: Regulator of Bone Remodeling and Biomarker in Osteoporosis}

Recent studies have found that miRNAs also play a critical regulatory role in remodeling bone formation and are involved in metabolic bone disorders (140). miRNAs such as miR-223, miR-103a, and miR-140 have been reported to regulate bone metabolism by modulating bone formation, reabsorption, and osteoblast-osteoclast activity $(140,141)$. miRNA expression profiling data in osteoporosis and osteoporotic fracture patients have clearly described that miRNAs play a crucial role in bone metabolism. miR-2861 regulates osteogenic differentiation of bone marrow mesenchymal stem cells (BMSCs), whereas miR-503 downregulates expression of the receptor activator of nuclear factor $-\kappa B$ (RANK), which ultimately leads to suppression of osteoclastogenesis in CD14 + peripheral blood mononuclear cells (PBMCs). Altogether, miRNA is an indispensable regulator in bone biology and can be used in a therapeutic strategy (142).

\section{microRNAs: Potential Therapeutic Targets for Cerebral Ischemia}

As miRNAs have the potential to degrade and suppress mRNAs, they are extensively selected as targets in diagnostic and therapeutic biology. Table 1 shows preferred miRNA targets in current diagnostics and therapeutics. Recent findings have shown that miRNA has an important role in regulation of occurrence and progression of cerebral ischemia (143). It has also been reported that circulating miRNAs in peripheral blood are deregulated in cerebral ischemia, to act as useful biomarkers for diagnosis and prognosis of this disease (144). miRNA gene-associated single nucleotide polymorphism (SNP) is responsible for complex functional consequences by involving miRNA biogenesis or various target selection. Recent studies on miRNA-SNP have shown a significant correlation between miRNA and progression of ischemic disease, which defines miRNA as potential biomarker and diagnostic and therapeutic target for cerebral ischemic disease $(143,145)$

\section{Hybridization-Mediated Off-Target Effects}

Currently, 28,645 miRNAs are listed in miRBase. On the basis of quantitative and biochemical assays, approximately 200-250 miRNAs possess high expression, which can be used as a potential target for mechanistic and therapeutic studies. Among them, some miRNAs are from the same family, having a homologous seed region, so that anti-miRs are generally unable to differentiate between miRNAs from the same group with similar seed regions. This lack of target specificity can lead to differences in antisense-associated inhibition of mRNAs and miRNAs. On the other hand, it is important to be cautious about the potential of specific anti-miRs to cross-inhibit molecules with identical seed regions at the time of a single mRNA-targeted therapeutic development. Researchers have shown that biosynthesis and maturation of miRNA could be inhibited by morpholinos in a miRNA-specific manner. On the basis of experimental data, it was reported that $m i R-375$ inhibition could lead to distorted morphology of pancreatic islet cells $(146,147)$. Biochemically modified oligos have been tested for target mRNA binding, inhibition of its splicing, and translation in mammalian systems and are under clinical trial. As miRNA biosynthesis is a multistep cascade process, its secondary structure is necessary for recruitment of associated enzymes. An identical process can be applied to targeting miRNA expression by disruption of synthesis of its precursor, which can be an efficient strategy to solve the limitations behind targeting mature mRNAs (109).

\section{Hybridization-Independent Off-Target Effects}

anti-miRNA and carrier molecules can be recognized by both innate and adaptive arms of the mammalian immune system. Effects of immune-stimulatory off target are of serious notable toxicological concern to oligonucleotide therapeutics. Researchers have shown that the siRNA sense strand, which is fully complementary to RISC-bound miRNA, mediates immune stimulatory response (148). Replacement of the sense strand nucleotides with poly, which is not immunostimulatory, promotes recognition of nine nucleotides in the $3^{\prime}$ end of the sense strand, which promotes TLR3 (toll-like receptor 3) activation (149). Although chemically modified oligonucleotides are necessary to enhance their affinity for RNA binding and nuclease resistance, these modifications are known to induce sequence-independent toxicity in vivo. Common consequences such as inhibition of coagulation and complement cascade activation of immune cells have been observed in this process. Phosphorothionate-containing oligonucleotides can inhibit coagulation and transiently enhance prolonged clotting time in monkeys (109). This effect is associated with plasma concentration but devoid of sequence. So it is a major concern to improve the pharmacokinetic and pharmacodynamic profiles of oligonucleotide and to develop more efficient systems for delivery, enhance the therapeutic approach, and avoid the coagulation effect. On the other hand, it has been shown that hepatotoxicity can be induced in a sequence-independent manner, as several LNAs targeting different molecules, as well as mismatched nontargeting control oligonucleotides, revealed identical issues related to toxicity. These findings highlight the necessity for careful evolution of modulated chemical combinations to generate a robust antisense oligonucleotide (ASO) molecule with less toxicity $(109,150)$.

\section{OVERCOMING OBSTACLES DURING microRNA DELIVERY}

Recently, it has been reported that several miRNAs are potentially involved in onset of disease and its progression (mainly cancer). Based on disease and tissue targeting, several strategies should be carefully considered to achieve the desired efficient anti-miR 
Table 1. Preferred miRNA targets in current diagnostics and therapeutics.

\begin{tabular}{|c|c|c|}
\hline microRNA & Association with therapeutics & Target and function \\
\hline miR-15 & $\begin{array}{l}\text { Cardiac ventricle regeneration } \\
\text { Chronic lymphocytic leukemia }\end{array}$ & $\begin{array}{l}\text { Target for suppression of ventricle regeneration during postnatal } \\
\text { switch }(1,2)\end{array}$ \\
\hline miR-21 & Hematopoietic tumors, fibrosis & oncomiRNA (3) \\
\hline $\operatorname{miR}-25$ & $\begin{array}{l}\text { Gastric cancer, Heart failure, } \\
\text { glioblastoma, lung cancer, prostate } \\
\text { cancer }\end{array}$ & Upregulation leads to gastric cancer and heart failure (4-6) \\
\hline miR-29b & $\begin{array}{l}\text { Acute lymphocytic leukemia, ovarian } \\
\text { cancer }\end{array}$ & Tumor suppression, C-KIT inhibition $(7,8)$ \\
\hline miR-33 & Metabolic disease, vascular disease & $\begin{array}{l}\text { Raising } H D L \text { levels by anti-miR-mediated inhibition of miR-33 } \\
\text { through its effects on cholesterol transport and atherosclerosis } \\
\text { regression }(9,10)\end{array}$ \\
\hline $\operatorname{miR}-34 \mathrm{~b} / \mathrm{c}$ & Lung cancer & Tumor suppression (11) \\
\hline miR-92a & Neoangiogenesis & $\begin{array}{l}\text { AntagomiR administration resulted in enhanced blood vessel } \\
\text { growth, functional improvement of damaged tissue in models of } \\
\text { hind limb ischemia and myocardial infarction (12) }\end{array}$ \\
\hline miR-103 & $\begin{array}{l}\text { Insulin sensitivity, biomarker for } \\
\text { colorectal cancer }\end{array}$ & Involved in dysregulation of glucose homeostasis $(13,14)$ \\
\hline miR-122 & HCV infection & Liver-specific, modulates HCV infection (15) \\
\hline miR-140 & Bone cancer & $\begin{array}{l}\text { miR-140-mediated cellular pathways may be reactivated } \\
\text { or inhibited for treating skeletal injury or dysfunction in } \\
\text { adulthood (16) }\end{array}$ \\
\hline miR-148 & Gastric cancer & MiR-148a down-regulation leads to gastric cancer.(17) \\
\hline miR-150 & $\begin{array}{l}\text { Acute myeloid leukemia, pancreatic } \\
\text { cancer; }\end{array}$ & Tumor suppressor, targets FLT3 and Myb $(18,19)$ \\
\hline miR-155 & Breast cancer, inflammatory diseases & $\begin{array}{l}\text { Tumor suppression by downregulating RAD51 and cancer cell } \\
\text { sensitization }(20,21)\end{array}$ \\
\hline miR-181a/b & Acute myeloid leukemia & Prevents tumor cell growth (22) \\
\hline miR-183 & $\begin{array}{l}\text { Insulin resistance and other hepatic } \\
\text { dysfunction }\end{array}$ & Insulin signaling (23) \\
\hline miR-195 & $\begin{array}{l}\text { Heart regeneration, diabetic } \\
\text { cardiomyopathy }\end{array}$ & $\begin{array}{l}\text { Inhibits heart regeneration, reduces diabetic cardiomyopathy } \\
(24,25)\end{array}$ \\
\hline miR-208 & Cardiac disease & Involved in hypertension and heart failure (26) \\
\hline miR-221 & Hepatocellular carcinoma & Targets p57 and p27, oncomiRNA (27) \\
\hline miR-375 & Breast cancer & Forced expression can resensitize cells (28) \\
\hline miR-451 & $\begin{array}{l}\text { Myeloproliferative diseases, lung } \\
\text { cancer }\end{array}$ & $\begin{array}{l}\text { miR-451-deficient erythroblasts due to upregulation of this miRNA } \\
\quad(29,30)\end{array}$ \\
\hline miR-467 & $\begin{array}{l}\text { Hyperglycemia-induced angiogenesis, } \\
\text { breast cancer }\end{array}$ & Inhibits tumor growth and angiogenesis (31) \\
\hline miR-494 & Lung cancer & Modulates cell proliferation and apoptosis (32) \\
\hline miR-495 & $\begin{array}{c}\text { Gastric cancer, acute myeloid } \\
\text { leukemia, medulloblastoma }\end{array}$ & Can block cell migration and invasion $(33,34)$ \\
\hline
\end{tabular}

1. Porrello ER, et al. (2013) Regulation of neonatal and adult mammalian heart regeneration by the miR-15 family. Proc. Nat. Acad. Sci. U.S.A. 110:187-92.

2. Pekarsky Y, Croce CM. (2015) Role of miR-15/16 in CLL. Cell Death Differ. 22:6-11.

3. Hugo S, et al. (2013) Targeting miR-21 Induces Autophagy and Chemosensitivity of Leukemia Cells. Current Drug Targets. 14: $1135-43$.

4. Zhao H, Wang Y, Yang L, Jiang R, Li W. (2013) miR-25 promotes gastric cancer cells growth and motility by targeting RECK. Mol. Cell. Biochem. 385:207-13. 
Table 1. Continued.

5. Wahlquist C, et al. (2014) Inhibition of miR-25 Improves Cardiac Contractility in the Failing Heart. Nature. 508:531-35.

6. Zoni E, et al. (2015) miR-25 Modulates Invasiveness and Dissemination of Human Prostate Cancer Cells via Regulation of $\alpha v-$ and a6-Integrin Expression. Cancer Res. 75:2326-36.

7. Teng Y, et al. (2015) MicroRNA-29B (mir-29b) regulates the Warburg effect in ovarian cancer by targeting AKT2 and AKT3. Oncotarget. 6:40799-814.

8. Yan B, et al. (2015) The role of miR-29b in cancer: regulation, function, and signaling. Onco Targets Ther. 8:539-48.

9. Jamaluddin MS, et al. (2011) miRNAs: roles and clinical applications in vascular disease. Expert Rev, Mol. Diagn. 11:79-89.

10. Fernández-Hernando C, Ramírez CM, Goedeke L, Suárez Y. (2013) MicroRNAs in Metabolic Disease. Arterioscler. Thromb. Vasc. Biol. 33:178-85

11. Cortez MA, et al. (2016) PDL1 Regulation by p53 via miR-34. J. Nat. Cancer Inst. 108.

12. Zhang L, Zhou M, Qin G, Weintraub NL, Tang Y. (2014) MiR-92a regulates viability and angiogenesis of endothelial cells under oxidative stress. Biochem. Biophys. Res. Communic. 446:952-58.

13. Williams MD, Mitchell GM. (2012) MicroRNAs in Insulin Resistance and Obesity. Exper. Diabetes Res. 2012:8.

14. Geng L, et al. (2014) MicroRNA-103 Promotes Colorectal Cancer by Targeting Tumor Suppressor DICER and PTEN. Int. J. Mol. Sci. 15:8458-72.

15. Luna JM, et al. (2015) Hepatitis C virus RNA functionally sequesters miR-122. Cell. 160:1099-1110.

16. Green D, Dalmay T, Fraser William D. (2015) Role of miR-140 in embryonic bone development and cancer. Clin. Sci. 129:863-73.

17. Xia J, Guo X, Yan J, Deng K. (2014) The role of miR-148a in gastric cancer. J. Cancer Res. Clin. Oncol. 140:1451-56.

18. Fayyad-Kazan H, et al. (2013) Circulating miR-150 and miR-342 in plasma are novel potential biomarkers for acute myeloid leukemia. J. Translat. Med. 11:31.

19. Yang K, et al. (2015) A Decrease in miR-150 Regulates the Malignancy of Pancreatic Cancer by Targeting C-Myb and MUC4. Pancreas. 44:370-79.

20. Gasparini P, et al. (2014) Protective role of miR-155 in breast cancer through RAD51 targeting impairs homologous recombination after irradiation. Proc. Nat. Acad. Sci. U.S.A. 111:4536-41.

21. Bacci M, et al. (2016) miR-155 Drives Metabolic Reprogramming of ER+ Breast Cancer Cells Following Long-Term Estrogen Deprivation and Predicts Clinical Response to Aromatase Inhibitors. Cancer Res. 76:1615-26.

22. Su R, et al. (2015) MiR-181 family: regulators of myeloid differentiation and acute myeloid leukemia as well as potential therapeutic targets. Oncogene. 34:3226-39.

23. Motiño O, et al. (2015) Regulation of MicroRNA 183 by Cyclooxygenase 2 in Liver Is DEAD-Box Helicase p68 (DDX5) Dependent: Role in Insulin Signaling. Mol. Cell. Biol. 35:2554-67.

24. Porrello ER, Olson EN. (2014) A neonatal blueprint for cardiac regeneration. Stem Cell Res. 13:556-70.

25. Zheng D, et al. (2015) Silencing of miR-195 reduces diabetic cardiomyopathy in C57BL/6 mice. Diabetologia. 58:1949-58.

26. Schulte C, Zeller T. (2015) microRNA-based diagnostics and therapy in cardiovascular disease-Summing up the facts. Cardiovasc. Diag. Ther. 5:17-36.

27. Zhang W, et al. (2015) Targeted delivery of chemically modified anti-miR-221 to hepatocellular carcinoma with negatively charged liposomes. Int. J. Nanomed. 10:4825-36.

28. Zehentmayr F, et al. (2016) Hsa-miR-375 is a predictor of local control in early stage breast cancer. Clin. Epigen. 8:28.

29. Bruchova-Votavova H, Yoon D, Prchal JT. (2010) miR-451 enhances erythroid differentiation in K562 cells. Leukemia Lymphoma. 51:686-693.

30. Yin P, et al. (2014) MiR-451 Suppresses Cell Proliferation and Metastasis in A549 Lung Cancer Cells. Mol. Biotechnol. 57: 1-11.

31. Krukovets I, Legerski M, Sul P, Stenina-Adognravi O. (2015) Inhibition of hyperglycemia-induced angiogenesis and breast cancer tumor growth by systemic injection of microRNA-467 antagonist. FASEB J. 29:3726-36.

32. Mao G, et al. (2015) Tumor-derived microRNA-494 promotes angiogenesis in non-small cell lung cancer. Angiogenesis. 18:373-82.

33. Jiang $X$, et al. (2012) miR-495 is a tumor-suppressor microRNA down-regulated in MLL-rearranged leukemia. Proc. Nat. Acad. Sci. U.S.A. 109: 19397-402.

34. Wang C, Yun Z, Zhao T, Liu X, Ma X. (2015) MiR-495 is a Predictive Biomarker that Downregulates GFI1 Expression in Medulloblastoma. Cell. Physiol. Biochem. 36:1430-39.

delivery. Tissues from organs such as kidney, liver, spleen, and lung are more easily accessible than from other organs, which provide sufficient delivery by antisense oligonucleotides without using carriers, whereas chemically formulated carrier molecule is needed to deliver
ASOs in solid tumors (151). It has been shown that overexpression of miR17-92, a highly induced miRNA in solid tumors and hematological malignancies, increases cell proliferation and suppression of apoptosis by affecting the BCL-2 interacting mediator, phosphatase, and tensing homologue and expression of the p21 gene $(152,153)$. Thus targeting such miRNAs is a reasonable approach for tumor growth inhibition. Therefore, different types of conditions need to be considered in order to develop such targeting system. First, as the anti-miRNAs 
are negatively charged, the nanoparticles should be positively charged for efficient binding (109). Second, the nanoparticles should be encoded with targeting molecules, which can efficiently and selectively contact with target cell surface-associated antigen. The outer surface of the nanoparticle should possess hydrophilic groups, so that it can bypass the rapid clearance through the reticuloendothelial system and increase circulation time after injection into the bloodstream. Last, the size of the final complex should be within $100 \mathrm{~nm}$ in diameter, along with uniform size distribution, and big enough to prevent rapid clearance through the kidney but small enough to penetrate the target tissue. On the other hand, there is another limitation, how to reach a significant dose inside the cell to achieve efficient inhibition of miRNA. These limitations can be listed as follows: 1) slow penetration of miRNAs into tumor tissues due to mechanical and biological barriers, 2) quick degradation of unprocessed miRNA mimics and miRNA antagonists and clearance from the blood circulation, 3) miRNA (ssRNA or dsRNA homologue)-mediated immunotoxicity, 4) neurotoxicity due to exposure to miRNAs, 5) inefficient gene silencing due to poor intracellular delivery and aggregation of naked miRNAs within the endosomes, 6) miRNA-mediated off-target effects, 7) altered function of therapeutic miRNAs due to saturated or insufficient miRNA processing enzymes (154-157).

Clinical trials are ongoing and several therapeutics-associated companies are engaged in overcoming these challenges to accomplish the most efficient result (109). Synthesis and development of miRNA-mediated therapeutics in commercial industries are listed in Table 2.

\section{In Vivo microRNA Delivery Strategies in Cancer Therapeutics}

Prolonged research has been ongoing to explore the features of tumors and tumor microenvironments for efficient and improved miRNA delivery. Notably, there are two types of strategies to deliver miRNA in vivo, local and systemic delivery (158).

Local Delivery of miRNAs. Local administration of miRNAs (with or without carriers) and intratumor injection are used to demonstrate antitumor effects and moderate gene silencing. Higher bioavailability can provide desired gene silencing by local miRNA delivery. Interestingly, it has been shown that local delivery of miRNA expresses less toxicity than systemic delivery (121).

Several types of local delivery strategies have been developed, which range from direct intramural injection of miRNA vector to formulation of nanoparticles with modified surface properties. In glioblastoma multiforme, intracranial delivery of miRNA is used for treatment (158)

Topical delivery for skin disease provides easy accessibility to the target region and a focused and potential systemic delivery with fewer side effects. Researchers have experimentally shown gene silencing by penetrating the skin with a spherical nanoparticle conjugate (SNA-Ncs) with modified gold cores and covalently immobilized siRNA (160) (optical delivery of siRNA-based spherical nucleic acid nanoparticle conjugates for gene regulation). We concluded that it is a promising effective delivery system in skin cancer therapeutic study (161).

Scientists have also shown that modified miRNA can be used for efficient miRNA delivery. Some siRNAs can act as miRNA antagonists or miRNA inducers, which can be delivered intratumorally in cancer therapeutics. For example, $c-m y c$ is downregulated by NP-DCAMK-1 saran, and notch-1 expression is regulated by upregulation of let-7a and miR-144 miRNA expression in the colorectal cancer engraft model. This xenograft model ultimately leads to inhibition of tumor growth. As a limitation, it has been proposed that local delivery is not an effective option for late-stage metastatic tumor. So it is important to establish a well-developed systemic delivery strategy to meet the current need for miRNA-mediated cancer therapy (162).

Systemic delivery of microRNAs. Nanoparticle-based delivery of siDCAMKL-1 increases miR-144 and inhibits colorectal cancer tumor growth via a notch-1-dependent mechanism.

Several systemic delivery strategies are in the pipeline to overcome the obstacles of in vivo miRNA delivery to achieve the most efficient result in cancer therapeutics. A widely used strategy developed for synthetic delivery of miRNA into tumors is to synthesize chemically modified miRNAs or miRNA antagonists such as anti-miRNA oligonucleotides (AMOs) (163).

The modified miRNA antagonists and miRNA mimics can protect themselves from nuclease degradation in circulation. On the other hand, a targeting moiety for intercellular uptake is necessary for this modified miRNA. Along with this, the small-modified miRNA may have rapid clearance through renal and hepatic systems, resulting in short half-lives (164).

Another delivery strategy has been established by designing nanoparticle formulation for passive diffusion with increased permeability and retention.

Other systemic strategies include modification of miRNA antagonists and miRNA mimics, modification of the $2^{\prime}$ $\mathrm{OH}$ group, locked nucleic acid modification, modification of the passenger strand, virus-mediated miRNA delivery, nonviral miRNA delivery, inorganic nanoparticle-based miRNA delivery, polymer-based synthetic miRNA delivery, and miRNA delivery using liposome $(132,155,156,165,166)$.

\section{USING EXOSOMES AS A DELIVERY VEHICLE}

There are several traditional methods, such as direct cell-to-cell contact, chemical receptor-mediated communication, and cell-cell synapse, used for cell-cell communication. Recent studies have discovered that delivery of RNA by exosomes through systemic circulation is an identical process to 
MICTORNA IN THERAPY

Table 2. Synthesis and development of miRNA-mediated therapeutics in commercial industries.

\begin{tabular}{|c|c|c|c|c|}
\hline Company & Aim and target & $\begin{array}{c}\text { Associated disease and } \\
\text { therapeutics }\end{array}$ & $\begin{array}{l}\text { Target miRNA and } \\
\text { function }\end{array}$ & Reference \\
\hline $\begin{array}{l}\text { Marina Biotech } \\
\text { (Bothell, WA, USA) }\end{array}$ & $\begin{array}{l}\text { Nucleic acid-based } \\
\text { therapeutics } \\
\text { (conformationally } \\
\text { restricted nucleotide) and } \\
\text { liposomal-based delivery } \\
\text { methods }\end{array}$ & $\begin{array}{l}\text { Therapeutics for familial } \\
\text { adenomatous polyposis, } \\
\text { bladder cancer, and } \\
\text { hepatocellular carcinoma }\end{array}$ & miR-122, miR-21 & $\begin{array}{l}\text { http://www.marinabio. } \\
\text { com/pipeline/ } \\
\text { nucleic-acid-drugs/ } \\
\text { Rooij et al. }(1,2)\end{array}$ \\
\hline $\begin{array}{l}\text { Rosetta Genomics } \\
\text { (Rehovot, Israel) }\end{array}$ & $\begin{array}{l}\text { MiRNA-based diagnostic } \\
\text { tests }\end{array}$ & $\begin{array}{l}\text { Cancer diagnostics (e.g., } \\
\text { lung, renal, bladder, } \\
\text { mesothelioma) }\end{array}$ & $\begin{array}{l}\text { Mimic of naturally } \\
\text { occurring } \\
\text { microRNA-34 }\end{array}$ & $\begin{array}{l}\text { https://rosettagx.com/ } \\
\text { technology/microrna } \\
\text { Rooij et al.(2) }\end{array}$ \\
\hline $\begin{array}{l}\text { Regulus Therapeutics } \\
\text { (Carlsbad, CA, USA) }\end{array}$ & $\begin{array}{l}\text { Alport syndrome treatment } \\
\text { development }\end{array}$ & Kidney dysfunction & $\begin{array}{l}\text { Inhibition of miRNA- } \\
21 \text { by RG-012 }\end{array}$ & $\begin{array}{l}\text { http://www.regulusrx. } \\
\text { com. }\end{array}$ \\
\hline Regulus Therapeutics & $\begin{array}{l}\text { Preclinical developing stage } \\
\text { for RG-101 }\end{array}$ & HCV infection & $\begin{array}{l}\text { GalNAc-conjugated } \\
\text { anti-miR targeting } \\
\text { microRNA-122 }\end{array}$ & $\begin{array}{l}\text { http://www.regulusrx. } \\
\text { com. }\end{array}$ \\
\hline $\begin{array}{l}\text { Asuragen, (Austin, TX, } \\
\text { USA) }\end{array}$ & Phase $1 \mathrm{~b}$ and 2 trials in 2016 & $\begin{array}{l}\text { Hepatocellular carcinoma, } \\
\text { other solid tumors and } \\
\text { hematologic malignancies }\end{array}$ & $\operatorname{miRX34}$ & www.miRNArx.com. \\
\hline Regulus Therapeutics & Preclinical stage & $\begin{array}{l}\text { Immunoinflammatory, } \\
\text { cardiovascular, metabolic } \\
\text { disease, oncology, fibrosis } \\
\text { and hepatitis C infection }\end{array}$ & $\begin{array}{l}\text { miRNA inhibitors using } \\
\text { 2'-methoxyethyl, } \\
\text { 2'-fluoro RNA, } \\
\text { bicyclic ribose } \\
\text { modifications }\end{array}$ & $\begin{array}{l}\text { http://www.regulusrx. } \\
\text { com. } \\
\text { Li et al.(3) }\end{array}$ \\
\hline $\begin{array}{l}\text { Santaris Pharma } \\
\text { (Hørsholm, } \\
\text { Denmark, and San } \\
\text { Diego, CA, USA) }\end{array}$ & $\begin{array}{l}\text { RNA-targeted therapeutics } \\
\text { (locked nucleic acid } \\
\text { platform); miR-122 } \\
\text { inhibitor: Phase I } \\
\text { completed, Phase II } \\
\text { initiated }\end{array}$ & $\begin{array}{l}\text { Therapeutics for metabolic } \\
\text { disorders (e.g., diabetes and } \\
\text { cardiovascular disease), } \\
\text { infectious and inflammatory } \\
\text { diseases (e.g., HCV } \\
\text { infection), cancer, and rare } \\
\text { genetic disorders }\end{array}$ & $\begin{array}{l}\text { miR-122 targeted; } \\
\text { miRNA inhibitors } \\
\text { using locked } \\
\text { nucleic acid } \\
\text { chemistry }\end{array}$ & $\begin{array}{l}\text { http://www.roche.com/ } \\
\text { index.htm } \\
\text { Rooij et al.(2) }\end{array}$ \\
\hline $\begin{array}{l}\text { miRagen Therapeutics } \\
\text { (Boulder, CO, USA) }\end{array}$ & Preclinical & $\begin{array}{l}\text { Therapeutics for } \\
\text { cardiovascular and muscle } \\
\text { diseases, polycythemia vera, } \\
\text { and metabolic disease }\end{array}$ & $\begin{array}{l}\text { miRNA (miR-208, } \\
15,451,29,92 \\
143,145,206,378) \\
\text { inhibition and } \\
\text { replacement }\end{array}$ & Rooij et al.(2) \\
\hline MiRNA Therapeutics & $\begin{array}{l}\text { Clinically tested MRX34(anti- } \\
\text { miR-34) development }\end{array}$ & $\begin{array}{l}\text { Non-small cell lung cancer, } \\
\text { prostate cancer, and } \\
\text { myeloma }\end{array}$ & miR-34 as oncogene & $\begin{array}{l}\text { http://www. } \\
\text { miRNAtherapeutics. } \\
\text { com/pipeline/miRNA- } \\
\text { MRX34.html }\end{array}$ \\
\hline $\begin{array}{l}\text { RXi Pharmaceuticals } \\
\text { (Worcester, MA, } \\
\text { USA) }\end{array}$ & $\begin{array}{l}\text { RNAi therapeutic } \\
\text { compounds (self- } \\
\text { delivering RNAi) }\end{array}$ & $\begin{array}{l}\text { Therapeutics for fibrosis and } \\
\text { reduction of dermal scarring }\end{array}$ & & $\begin{array}{l}\text { http://www.rxipharma. } \\
\text { com/ } \\
\text { Rooij et al. }\end{array}$ \\
\hline
\end{tabular}

1. van Rooij E, Kauppinen S. (2014) Development of microRNA therapeutics is coming of age. EMBO Mol. Med. 6:851-64.

2. van Rooij E, Purcell AL, Levin AA. (2012) Developing MicroRNA Therapeutics. Circ. Res. 1 10:496-507.

3. Li Z, Rana TM. (2014) Therapeutic targeting of microRNAs: current status and future challenges. Nat. Rev. Drug. Discov. 13:622-38. 
hormonal action. It has also been demonstrated that miRNA participates in RNA granule formation, stress granule synthesis, processing bodies, and glycine-tryptophan-rich cytoplasmic bodies (GW bodies), which are involved in posttranscriptional modification and epigenetic modulation. The interaction of GW bodies and RNA granules is a crucial step for releasing miRNA during endosome formation (167). Earlier studies suggested that miRNA could be loaded efficiently into exosomes and actively transferred by exosomes (168). Figure 5 shows the schematic representation of cytoplasmic miRNA trafficking in the endosomal-exosomal cascade pathway. Exosomes delivering miRNAs to respective cells makes them an ideal transport for gene therapy, so that specific RNA-containing exosomes will need to be modified accordingly. Nowadays, miRNA trafficking through exosomes is a widely used model for studying tumor and neuronal diseases (Figure 5) (169).

\section{Artificial microRNAs and microRNA Technology}

Aberrant expression of miRNAs is associated with several human multigenic diseases and can serve as a biomarker for diagnostics. High-resolution expression profiling of miRNAs in cancer cell lines and human tumors suggests that miRNA signatures may be useful in categorizing, detecting, and predicting the course of human cancers (170). miRNA expression profiles can be used to distinguish the lineage of solid tumors and classify poorly differentiated cancer specimens (171). Asuragen has launched a qRTPCR-based miRNA diagnostic test for differentiation between chronic pancreatitis and pancreatic cancer patients. A bloodbased noninvasive miRNA signature assay has been developed for detection of malignant lung cancer. Rosetta Genomics has launched a miRNA-based diagnostic test for identification of the primary origin of cancer of uncertain or unknown origin. This test offers a wide panel of 42 identifiable tumor origins for accurate classification. Targeting them with artificial
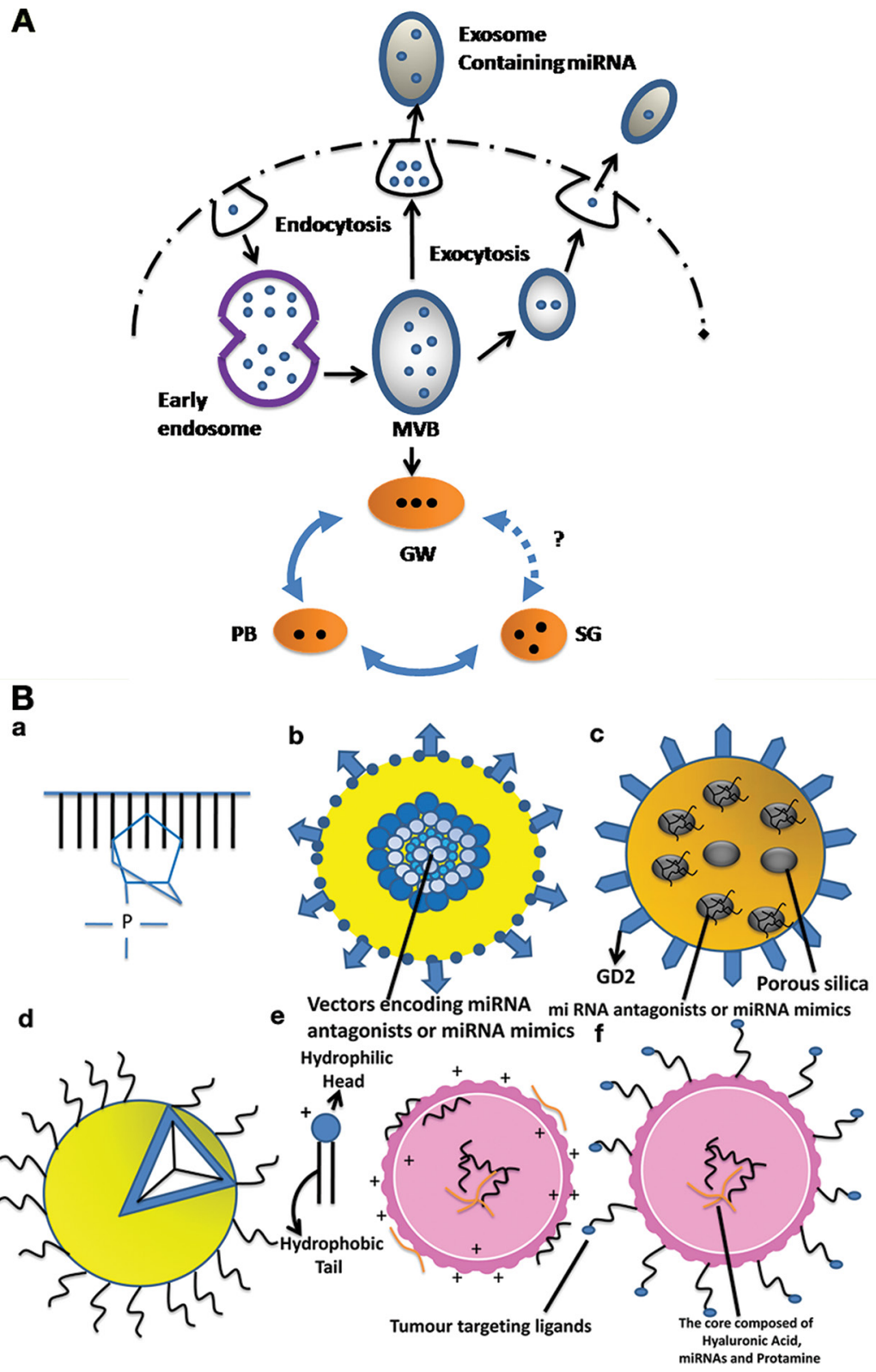

Figure 5. (A) Trafficking and delivery vehicle of miRNA in cells, the specific miRNA endocy-toses into endocytic vesicles that generate early endosome. Many endogenous miRNAs are involved in RNA granule formation, including glycine and tryptophane-rich bodies (GW), processing bodies (PB), and stress granules (SG), which invariably fuse with multi-vesicular bodies (MVB) and the plasma membrane. Then exosomes are released through exocytosis into the extracellular space. Reproduced with permission (169). (B) Different processes for miRNA delivery in vivo. Numerous strategies, including modified miRNA, antagonistic or miRNA mimics, viral vector, organic and nonorganic viral vectors were used for therapeutic delivery. (a-f) Different types of modified nanoparticles are used for miRNA delivery. (b) Viral vector system for delivery (c) Silica nano particles used for delivering in overexpressed tumors; (d) Polymer based organic non-viral vector for gene therapy; (e) nano particle based on liposome; ( $f$ ) modulated with anti-bodies or ligand for cancer associated delivery. Figure reproduced with permission of Elsevier B.V. Chen Y, Gao D-Y, Huang L. (2015) In vivo delivery of miRNAs for cancer therapy: Challenges and strategies. Adv. Drug Del. Rev. 81:128-41. (cited as reference (156) in the current review). 
antisense RNAs called antagomiRs may reduce miRNA levels. Stability of antagomiRs is increased by modifications such as a $2^{\prime} O$-methyl modification that renders them resistant to nucleases and provides high thermodynamic duplex stability. AntagomiRs ASOs are sequence-specific and long-lasting and have little or no shortterm toxicity $(105,172)$. Scientists have shown that targeting miR-122 in the mouse liver using an anti-miR-122 antagomiR results in complete degradation of $m i R-122$ in a dose-dependent manner (133). Alternatively, miRNA target mimics (also called miRNA Sponge, miRZip, or Tough Decoy RNAs) could also be used to downregulate the effect of miRNA $(173,174)$.

\section{Future Perspective}

The most tedious question to address is in regard to the major appropriate resistant mechanisms to control miRNA-regulated fine-tuning in therapy. There are four distinct mechanisms: 1) absorption, spreading, and metabolic potential effective in controlling genes and liberating chemically generated anti-miRs; 2) synthesizing ample small chemical molecules that modulate targeted $m i R ; 3)$ up- and downregulation of miRNA effects, biogenesis, and processing; and 4) upregulation of off-target-related miRNA that can modulate the same gene, thereby counteracting miRNA inhibition. These factors promote optimization of miRNA targeting strategies to develop nextgeneration miRNA therapies.

In miRNA therapy, we have developed more efficient delivery vehicles, which are the major hurdles for miRNA incorporation in live cells and embryos. The development of efficient vehicles allows entering into specific organs, tissues, and cell types. To date, development for vehicles including liposome-encapsulated structures, organic nanotubes, nanoparticles, and naked oligonucleotides has been operated by microRNA-conjugated molecules, particularly in the liver, spleen, kidney, and other soft tissues. Moreover, some of the oligonucleotides can be incorporated via intravenous or subcutaneous routes. Invariably, oral delivery via organic nanotubes is a unique step for delivery of miRNA drugs in patient (175). In this view, it is reasonably interesting to determine whether miRNA-related therapies could be combined with biological or chemical drugs for multidrug therapy. Many miRNA therapies for resistant cancers exhibit an aggressive deterioration of health with weak prognosis. A combination treatment approach will reduce the risk of multi-miRNA-regulated diseases. This approach will demonstrate how multiple miRNA treatments influence target gene expression.

Despite extraordinary obstacles, we have arrived at the realm where different small molecules mimic or inhibit different disease-related miRNAs associated with numerous aspects of human diseases. We expect that many molecules will be characterized functionally via clinical development and epigenetic factors that provide new vistas of clinical challenges and treatment in the future.

\section{CONCLUSIONS}

Despite so much information generated in past two decades regarding miRNA biogenesis, maturation process, complex ways in which miRNA functions, and its role in therapeutics, we probably perceive only the tip of the iceberg. We are beginning to understand the regulatory aspects of miRNA biogenesis, the progression of disease, and the diversity in the types of small RNA transcripts. These noncoding RNAs are a predominant class of regulatory RNAs, but mostly they have been indicated as an integrative resource of the biochemical mechanisms for their function in gene regulation. On the other hand, genetic screens are continuously discovering newer modifiers of miRNA and other small RNA pathways. The widespread roles of miRNA in development, diseases, and infections, and the experimentally validated utility of artificial miRNAs immediately suggest immense potential in therapeutics, genetic improvement of livestock, resistance to pathogenic infections, association with neurodegenerative and cardiac diseases, bone remodeling, and possibly increased shelf life of animal products. Use of miRNA as a technology holds a lot of promise for a wide spectrum of diagnostic and therapeutic possibilities, which at the same time necessitates further work for better understanding of this relatively nascent field to achieve the best consequences.

\section{ACKNOWLEDGMENTS}

This work was sponsored by the Council of Scientific and Industrial Research network project to UB (BSC 0108, BSC 0121) and the DBT Drosophila project to MPB (GAP0362). We thank all the members of the UB Lab for their critical comments on the manuscript. We dedicate the manuscript to the memory of a great educator and novel teacher, Mr. Kalipada Bhadra, and his wife, Maya Lata Bhadra.

\section{DISCLOSURE}

The authors declare that they have no competing interests as defined by Molecular Medicine or other interests that might be perceived to influence the results and discussion reported in this paper.

\section{REFERENCES}

1. Park JH, Shin C. (2014) MicroRNA-directed cleavage of targets: mechanism and experimental approaches. BMB Reports. 47:417-23.

2. MacFarlane L-A, Murphy PR. (2010) MicroRNA: Biogenesis, Function and Role in Cancer. Curr. Genomics. 11:537-61.

3. Garg M. (2015) Emerging role of microRNAs in cancer stem cells: Implications in cancer therapy. World J. Stem Cells. 7:1078-89.

4. Dumortier O, Hinault C, Van Obberghen E. (2013) MicroRNAs and Metabolism Crosstalk in Energy Homeostasis. Cell Metab. 18:312-24.

5. Lewis MA, et al. (2009) An ENU-induced mutation of miR-96 associated with progressive hearing loss in mice. Nature Genetics. 41:614-18.

6. Israelow B, et al. (2014) Hepatitis C virus genetics affects miR-122 requirements and response to miR-122 inhibitors. Nat. Commun. 5:5408.

7. Starega-Roslan J, Galka-Marciniak P, Krzyzosiak WJ. (2015) Nucleotide sequence of miRNA precursor contributes to cleavage site selection by Dicer. Nucleic Acids Res. 43:10939-51.

8. Cai X, Hagedorn CH, Cullen BR. (2004) Human microRNAs are processed from capped, polyadenylated transcripts that can also function as mRNAs. RNA. 10:1957-66.

9. Hammond SM. (2005) Dicing and slicing: The core machinery of the RNA interference pathway. FEBS Letters. 579:5822-29. 
10. Bohnsack MT, Czaplinski K, Görlich D. (2004) Exportin 5 is a RanGTP-dependent dsRNAbinding protein that mediates nuclear export of pre-miRNAs. RNA. 10:185-91.

11. Nicholson AW. (2014) Ribonuclease III mechanisms of double-stranded RNA cleavage. Wiley Interdiscip. Rev. RNA. 5:31-48.

12. Carthew RW, Sontheimer EJ. (2009) Origins and Mechanisms of miRNAs and siRNAs. Cell. 136:642-55.

13. Lee HY, Zhou K, Smith AM, Noland CL, Doudna JA. (2013) Differential roles of human Dicerbinding proteins TRBP and PACT in small RNA processing. Nucleic Acids Res. 41:6568-76.

14. Taylor DW, et al. (2013) Substrate-specific structural rearrangements of human Dicer. Nat. Struct. Mol. Biol. 20:662-70.

15. Ha M, Kim VN. (2014) Regulation of microRNA biogenesis. Nat. Rev. Mol. Cell. Biol. 15:509-24.

16. Czech B, Hannon GJ. (2011) Small RNA sorting: matchmaking for Argonautes. Nature Rev. Genet. 12:19-31.

17. Tomari Y, et al. (2004) RISC Assembly Defects in the Drosophila RNAi Mutant Armitage. Cell. 116:831-41.

18. Fuller-Pace FV. (2006) DExD/H box RNA helicases: multifunctional proteins with important roles in transcriptional regulation. Nucleic Acids Res. 34:4206-15.

19. Chiang HR, et al. (2010) Mammalian microRNAs: experimental evaluation of novel and previously annotated genes. Genes Dev. 24:992-1009.

20. Miyoshi K, Okada TN, Siomi H, Siomi MC. (2009) Characterization of the miRNA-RISC loading complex and miRNA-RISC formed in the Drosophila miRNA pathway. RNA. 15:1282-91.

21. Xie M, Steitz JA. (2014) Versatile microRNA biogenesis in animals and their viruses. RNA Biol. 11:673-81.

22. Cifuentes $\mathrm{D}$, et al. A novel miRNA processing pathway independent of Dicer requires Argonaute2 catalytic activity. Science. 328:1694-98.

23. Yang JS, Lai EC. Dicer-independent, Ago2mediated microRNA biogenesis in vertebrates. Cell Cycle. 9:4455-60.

24. Brennecke J, Hipfner DR, Stark A, Russell RB, Cohen SM. (2003) Bantam Encodes a Developmentally Regulated microRNA that Controls Cell Proliferation and Regulates the Proapoptotic Gene Hid in Drosophila. Cell. 113:25-36.

25. Obernosterer G, Leuschner PJF, Alenius M, Martinez J. (2006) Post-transcriptional regulation of microRNA expression. RNA. 12:1161-67.

26. Liang R, Bates DJ, Wang E. (2009) Epigenetic Control of MicroRNA Expression and Aging. Curr. Genomics. 10:184-93.

27. Kim J, et al. (2007) A microRNA feedback circuit in midbrain dopamine neurons. Science. 317:1220-24.

28. Li J, Dani JA, Le W. (2009) The Role of Transcription Factor Pitx3 in Dopamine Neuron Development and Parkinson's Disease. Curr. Top. Med. Chem. 9:855-59.
29. Höck J, Meister G. (2008) The Argonaute protein family. Genome Biology. 9:210.

30. Cora E, et al. (2014) The MID-PIWI module of Piwi proteins specifies nucleotide- and strandbiases of piRNAs. RNA. 20:773-81.

31. Rice JB, Balasubramanian D, Vanderpool CK. (2012) Small RNA binding-site multiplicity involved in translational regulation of a polycistronic mRNA. Proc. Nat. Acad. Sci. U.S.A. 109: e2691-98.

32. Jonas S, Izaurralde E. (2015) Towards a molecular understanding of microRNA-mediated gene silencing. Nat. Rev. Genet. 16:421-33.

33. Hilgers V, Lemke SB, Levine M. (2012) ELAV mediates 3' UTR extension in the Drosophila nervous system. Genes Dev. 26:2259-64.

34. Franks TM, Lykke-Andersen J. (2007) TTP and BRF proteins nucleate processing body formation to silence mRNAs with AU-rich elements. Genes Dev. 21:719-35.

35. Borbolis F, Syntichaki P. (2015) Cytoplasmic mRNA turnover and ageing. Mech. Ageing Dev. 152:32-42.

36. Behm-Ansmant I, et al. (2006) mRNA degradation by miRNAs and GW182 requires both CCR4:NOT deadenylase and DCP1:DCP2 decapping complexes. Genes Dev. 20:1885-98.

37. Perron MP, Provost P. (2009) Protein components of the microRNA pathway and human diseases. Methods Mol. Biol. 487:369-85.

38. Eulalio A, Tritschler F, Izaurralde E. (2009) The GW182 protein family in animal cells: New insights into domains required for miRNAmediated gene silencing. RNA. 15:1433-42.

39. Sethi A, Kulkarni N, Sonar S, Lal G. (2013) Role of miRNAs in CD4 $\mathrm{T}$ cell plasticity during inflammation and tolerance. Front. Genet. 4:8.

40. Fukaya T, Tomari Y. (2012) MicroRNAs Mediate Gene Silencing via Multiple Different Pathways in Drosophila. Molecular Cell. 48:825-36.

41. Gu S, Kay MA. (2010) How do miRNAs mediate translational repression? Silence. 1:11.

42. Bader AG, Brown D, Winkler M. (2010) The Promise of MicroRNA Replacement Therapy. Cancer Res. 70:7027-30.

43. Grammatikakis I, Gorospe M, Abdelmohsen K. (2013) Modulation of Cancer Traits by Tumor Suppressor microRNAs. Int. J. Mol. Sci. 14:1822-42.

44. Aagaard L, Rossi JJ. (2007) RNAi Therapeutics: Principles, Prospects and Challenges. Adv. Drug Deliv. Rev. 59:75-86.

45. Bader AG. (2012) miR-34 - a microRNA replacement therapy is headed to the clinic. Front. Genet. 3:120.

46. Bader AG, Brown D, Stoudemire J, Lammers P. (2011) Developing therapeutic microRNAs for cancer. Gene Therapy. 18:1121-26.

47. Matranga C, Zamore PD. (2007) Small silencing RNAs. Curr. Biol. 17:R789-R793.

48. Bak RO, Hollensen AK, Mikkelsen JG. (2013) Managing MicroRNAs with Vector-Encoded Decoy-Type Inhibitors. Mol. Ther. 21:1478-85.

49. Chamorro-Jorganes A, Araldi E, Suárez Y. (2013) microRNAs as Pharmacological Targets in Endo- thelial Cell Function and Dysfunction. Pharmacol. Res. 75:15-27.

50. Schickel R, Boyerinas B, Park SM, Peter ME. (0000) MicroRNAs: key players in the immune system, differentiation, tumorigenesis and cell death. Oncogene. 27:5959-74.

51. Bertoli G, Cava C, Castiglioni I. (2015) MicroRNAs: New Biomarkers for Diagnosis, Prognosis, Therapy Prediction and Therapeutic Tools for Breast Cancer. Theranostics. 5:1122-43.

52. Ma L. (2010) Role of miR-10b in breast cancer metastasis. Breast Cancer Res. Treat. 12:210.

53. Shu M, et al. (2011) Targeting oncogenic miR-335 inhibits growth and invasion of malignant astrocytoma cells. Mol. Cancer Biol. 10:59.

54. Mott JL. (2009) MicroRNAs Involved in Tumor Suppressor and Oncogene Pathways; Implications for Hepatobiliary Neoplasia. Hepatology. 50:630-37.

55. Hung C-H, Chiu Y-C, Chen C-H, Hu T-H. (2014) MicroRNAs in Hepatocellular Carcinoma: Carcinogenesis, Progression, and Therapeutic Target. BioMed Res. Int. 2014:486407.

56. Hong L, et al. (2010) The miR-17-92 Cluster of microRNAs Confers Tumorigenicity by Inhibiting Oncogene-Induced Senescence. Cancer Res. 70:8547-57.

57. Monsalvez V, et al. (2013) MicroRNAs as prognostic markers in indolent primary cutaneous B-cell lymphoma. Mod. Pathol. 26:171-81.

58. Wei F, Cao C, Xu X, Wang J. (2015) Diverse functions of miR-373 in cancer. J. Transl. Med. 13:162.

59. Dorval V, Hébert SS. (2012) LRRK2 in Transcription and Translation Regulation: Relevance for Parkinson's Disease. Front. Neurol. 3:12.

60. Liu C, Tang DG. (2011) MicroRNA regulation of cancer stem cells. Cancer Res. 71:5950-5954.

61. Bao B, Ahmad A, Azmi AS, Ali S, Sarkar FH. (2013) Cancer Stem Cells (CSCs) and Mechanisms of Their Regulation: Implications for Cancer Therapy. Curr. Protoc. Pharmacol. 14:Unit 14.25.

62. Misso G, et al. (2014) Mir-34: A New Weapon Against Cancer? Mol. Ther. Nucleic Acids. 3: e195.

63. Wang SE, Lin R-J. (2013) MicroRNA and HER2-overexpressing Cancer. Microrna. 2:137-47.

64. Farooqi AA, Rehman Zu, Muntane J. (2014) Antisense therapeutics in oncology: current status. Onco Targets Ther. 7:2035-42.

65. Fassan M, Baffa R. (2013) MicroRNAs and targeted therapy: small molecules of unlimited potentials. Curr. Opin. Genet. \& Dev. 23:75-7.

66. Cheng CJ, et al. (2015) MicroRNA silencing for cancer therapy targeted to the tumor microenvironment. Nature. 518:107-10.

67. Kuninty PR, Schnittert J, Storm G, Prakash J. (2016) MicroRNA Targeting to Modulate Tumor Microenvironment. Front. Oncol. 6:3.

68. Andreopoulos B, Anastassiou D. (2012) Integrated Analysis Reveals hsa-miR-142 as a Representative of a Lymphocyte-Specific Gene Expression and Methylation Signature. Cancer Inform. 11:61-75.

69. Chan E, et al. (2011) MicroRNA signatures differentiate melanoma subtypes. Cell Cycle. 10:1845-52. 
70. Wang F, et al. (2012) miR-29a and miR-142-3p downregulation and diagnostic implication in human acute myeloid leukemia. Mol. Biol. Rep. 39:2713-22.

71. Zhao J-J, et al. (2010) microRNA expression profile and identification of miR-29 as a prognostic marker and pathogenetic factor by targeting CDK6 in mantle cell lymphoma. Blood. 115:2630-39.

72. Chaudhry MA, Sachdeva H, Omaruddin RA. (2010) Radiation-induced micro-RNA modulation in glioblastoma cells differing in DNA-repair pathways. DNA Cell Biol. 29:553-61.

73. Joyce CE, et al. (2011) Deep sequencing of small RNAs from human skin reveals major alterations in the psoriasis miRNAome. Hum. Mol. Gen. 20:4025-40.

74. Sun Y, et al. (2011) Targeting of microRNA$142-3 p$ in dendritic cells regulates endotoxininduced mortality. Blood. 117:6172-83.

75. Annoni A, et al. (2009) In vivo delivery of a microRNA-regulated transgene induces antigen-specific regulatory $\mathrm{T}$ cells and promotes immunologic tolerance. Blood. 114:5152-61.

76. Huang B, et al. (2009) miR-142-3p restricts cAMP production in CD4(+)CD25(-) T cells and CD4(+) CD25(+) T(REG) cells by targeting AC9 mRNA. EMBO Reports. 10:180-85.

77. Zhao J, et al. (2010) Selective Depletion of CD4+CD25+Foxp3+ Regulatory T Cells by Low-Dose Cyclophosphamide Is Explained by Reduced Intracellular ATP Levels. Cancer Res. 70:4850-58.

78. Bissels U, et al. (2011) Combined Characterization of microRNA and mRNA Profiles Delineates Early Differentiation Pathways of CD133(+) and CD34(+) Hematopoietic Stem and Progenitor Cells. Stem Cells. 29:847-57.

79. Wang X-S, et al. (2012) MicroRNA-29a and microRNA-142-3p are regulators of myeloid differentiation and acute myeloid leukemia. Blood. 119:4992-5004.

80. Lee H, Han S, Kwon CS, Lee D. (2016) Biogenesis and regulation of the let-7 miRNAs and their functional implications. Protein Cell. 7:100-13.

81. Takamizawa J, et al. (2004) Reduced Expression of the let-7 MicroRNAs in Human Lung Cancers in Association with Shortened Postoperative Survival. Cancer Res. 64:3753.

82. Johnson SM, et al. (2005) RAS Is Regulated by the let-7 MicroRNA Family. Cell. 120:635-47.

83. Wang X, et al. (2012) Regulation of let-7 and its target oncogenes (Review). Oncol. Lett. 3: 955-960.

84. Kasinski AL, Slack FJ. (2012) miRNA-34 prevents cancer initiation and progression in a therapeutically-resistant K-ras and p53-induced mouse model of lung adenocarcinoma. Cancer Res. 72:5576-87.

85. van Rooij E, Kauppinen S. (2014) Development of microRNA therapeutics is coming of age. EMBO Mol. Med. 6:851-64.

86. Hwang HW, Mendell JT. (2006) MicroRNAs in cell proliferation, cell death, and tumorigenesis. Br. J. Cancer. 94:776-80.
87. Bhadra U, et al. (2015) HDAC inhibitor misprocesses bantam oncomiRNA, but stimulates hid induced apoptotic pathway. Sci. Rep. 5:14747.

88. Maguire CA, Ramirez SH, Merkel SF, SenaEsteves M, Breakefield XO. (2014) Gene Therapy for the Nervous System: Challenges and New Strategies. Neurotherapeutics. 11:817-39.

89. Min X-1, et al. (2015) MicroRNAs: a novel promising therapeutic target for cerebral ischemia/reperfusion injury? Neural Regener. Res. 10:1799-1808.

90. Barbato C, Ruberti F, Cogoni C. (2009) Searching for MIND: MicroRNAs in Neurodegenerative Diseases. J. Biomed. Biotechnol. 2009:8.

91. Nelson PT, Wang W-X. (2010) MiR-107 is reduced in Alzheimer's disease brain neocortex: validation study. J. Alzheimers Dis. 21:75-79.

92. Grundhoff A, Sullivan CS. (2011) Virus-encoded microRNAs. Virology. 411:325-43.

93. Boissonneault V, Plante I, Rivest S, Provost P. (2009) MicroRNA-298 and microRNA-328 Regulate Expression of Mouse B-Amyloid Precursor Protein-Converting Enzyme 1. J. Biol. Chem. 284:1971-81.

94. Maciotta S, Meregalli M, Torrente Y. (2013) The involvement of microRNAs in neurodegenerative diseases. Front. Cell. Neurosci. 7:265.

95. Henshall DC. (2013) MicroRNAs in the pathophysiology and treatment of status epilepticus. Front. Mol. Neurosci. 6:37.

96. Chai C, Lim K-L. (2013) Genetic Insights into Sporadic Parkinson's Disease Pathogenesis. Curr. Genomics. 14:486-501.

97. Wang C, Ji B, Cheng B, Chen J, Bai BO. (2014) Neuroprotection of microRNA in neurological disorders (Review). Biom. Rep. 2:611-19.

98. Maes OC, Chertkow HM, Wang E, Schipper HM. (2009) MicroRNA: Implications for Alzheimer Disease and other Human CNS Disorders. Curr. Genomics. 10:154-68.

99. Singh M. (2012) Dysregulated A to I RNA editing and non-coding RNAs in neurodegeneration. Front. Genet. 3:326.

100. Mahishi LH, Hart RP, Lynch DR, Ratan RR. (2012) miR-886-3p Levels Are Elevated in Friedreich Ataxia. J. Neurosci. 32:9369-73.

101. Chen J, Wang D-Z. (2012) microRNAs in cardiovascular development. J. Mol. Cell. Cardiol. 52:949-57.

102. Fuller AM, Qian L. (2014) MiRiad Roles for MicroRNAs in Cardiac Development and Regeneration. Cells. 3:724-50.

103. Montgomery RL, et al. (2011) Therapeutic Inhibition of miR-208a Improves Cardiac Function and Survival During Heart Failure. Circulation. 124:1537-47.

104. Liu N, Olson EN. (2010) MicroRNA Regulatory Networks in Cardiovascular Development. Dev. Cell. 18:510-25.

105. Stenvang J, Petri A, Lindow M, Obad S, Kauppinen S. (2012) Inhibition of microRNA function by antimiR oligonucleotides. Silence. 3:1.

106. Notari M, Pulecio J, Raya Á. (2015) Update on the Pathogenic Implications and Clinical Potential of
microRNAs in Cardiac Disease. BioMed Res. Int 2015:105620.

107. Morrison JL, et al. (2015) Regulation of microRNA during cardiomyocyte maturation in sheep. BMC Genomics. 16:1-15.

108. Hullinger TG, et al. (2012) Inhibition of miR-15 Protects Against Cardiac Ischemic Injury. Circ. Res. 110:71-81.

109. Li Z, Rana TM. (2014) Therapeutic targeting of microRNAs: current status and future challenges. Nat. Rev. Drug. Discov. 13:622-38.

110. Alexander R, Lodish H, Sun L. (2011) MicroRNAs in adipogenesis and as therapeutic targets for obesity. Expert Opin. Ther. Targets. 15:623-36.

111. Lee S. (2013) Pharmacological Inhibition of Voltage-gated $\mathrm{Ca}(2+)$ Channels for Chronic Pain Relief. Curr. Neuropharmacol. 11:606-20.

112. Skalsky RL, Cullen BR. (2010) Viruses, microRNAs, and Host Interactions. Annu. Rev. Microbiol. 64:123-41.

113. Li C, et al. (2014) Competitive virus and host RNAs: the interplay of a hidden virus and host interaction. Protein Cell. 5:348-56.

114. Ouellet DL, Provost P. (2010) MicroRNAs and non-coding RNAs in virus-infected cells. Methods Mol. Biol. 623:35-65.

115. He Y, Yang K, Zhang X. (2014) Viral MicroRNAs Targeting Virus Genes Promote Virus Infection in Shrimp In Vivo. J. Virol. 88:1104-12.

116. Gupta A, Gartner JJ, Sethupathy P, Hatzigeorgiou AG, Fraser NW. (2006) Anti-apoptotic function of a microRNA encoded by the HSV-1 latency-associated transcript. Nature. 442:82-85.

117. Jovanovic M, Hengartner MO. (0000) miRNAs and apoptosis: RNAs to die for. Oncogene. 25:6176-87.

118. Lodish HF, Zhou B, Liu G, Chen C-Z. (2008) Micromanagement of the immune system by microRNAs. Nat. Rev. Immunol. 8:120-30.

119. Bivalkar-Mehla S, et al. (2011) Viral RNA Silencing Suppressors (RSS): Novel Strategy of Viruses to Ablate the Host RNA Interference (RNAi) Defense System. Virus Res. 155:1-9.

120. Li Y, Masaki T, Lemon SM. (2013) miR-122 and the Hepatitis C RNA genome: More than just stability. RNA Biol. 10:919-23.

121. Broderick JA, Zamore PD. (2011) microRNA Therapeutics. Gene Ther. 18:1104-10.

122. Nachmani D, Lankry D, Wolf DG, Mandelboim O. (2010) The human cytomegalovirus microRNA miR-UL112 acts synergistically with a cellular microRNA to escape immune elimination. Nat. Immunol. 11:806-13.

123. Hook L, et al. (2014) Cytomegalovirus microRNAs. Curr. Opin. Virol. 0:40-46.

124. O'Connor CM, Vanicek J, Murphy EA. (2014) Host MicroRNA Regulation of Human Cytomegalovirus Immediate Early Protein Translation Promotes Viral Latency. J. Virol. 88:5524-32.

125. Landais I, et al. (2015) Human Cytomegalovirus miR-UL112-3p Targets TLR2 and Modulates the TLR2/IRAK1/NFkB Signaling Pathway. PLoS Pathogens. 11: e1004881. 
126. Jung Y-J, Choi H, Kim H, Lee SK. (2014) MicroRNA miR-BART20-5p Stabilizes Epstein-Barr Virus Latency by Directly Targeting BZLF1 and BRLF1. J. Virol. 88:9027-37.

127. Mansouri S, Pan Q, Blencowe BJ, Claycomb JM, Frappier L. (2014) Epstein-Barr Virus EBNA1 Protein Regulates Viral Latency through Effects on let-7 MicroRNA and Dicer. J. Virol. 88: 11166-77.

128. Mahajan A, et al. (2010) HMGA2: A biomarker significantly overexpressed in high-grade ovarian serous carcinoma. Mod. Pathol. 23:673-81.

129. Sun X, et al. (2016) Let-7c blocks estrogenactivated Wnt signaling in induction of selfrenewal of breast cancer stem cells. Cancer Gene Ther. 23:83-89.

130. Di Leva G, Garofalo M, Croce CM. (2014) microRNAs in cancer. Annu. Rev. Pathol. 9: 287-314.

131. Lund E, Sheets MD, Imboden SB, Dahlberg JE. (2011) Limiting Ago protein restricts RNAi and microRNA biogenesis during early development in Xenopus laevis. Genes Dev. 25:1121-31.

132. Xie J, Burt DR, Gao G. (2015) AAV-mediated miRNA Delivery and Therapeutics. Semin. Liver Dis. 35:81-88.

133. Bandiera S, Pfeffer S, Baumert TF, Zeisel MB. (2015) miR-122 - A key factor and therapeutic target in liver disease. J. Hepatol. 62:448-57.

134. Merienne N, Douce JL, Faivre E, Déglon N, Bonvento G. (2013) Efficient gene delivery and selective transduction of astrocytes in the mammalian brain using viral vectors. Front. Cell. Neurosci. 7:106.

135. Merienne N, et al. (2015) Gene transfer engineering for astrocyte-specific silencing in the CNS. Gene Ther. 22:830-39.

136. Aurelie D, Carole E, Nicole D. (2013) Lentiviral Vectors: A Powerful Tool to Target Astrocytes In Vivo. Curr. Drug Targets. 14:1336-46.

137. Nemunaitis J, Edelman J. (2002) Selectively replicating viral vectors. Cancer Gene Ther. 9:987-1000.

138. Herberts CA, Kwa MSG, Hermsen HPH. (2011) Risk factors in the development of stem cell therapy. J. Translat. Med. 9:29.

139. Ebert MS, Sharp PA. (2010) MicroRNA sponges: Progress and possibilities. RNA. 16:2043-50.

140. Sun M, et al. (2016) The Regulatory Roles of MicroRNAs in Bone Remodeling and Perspectives as Biomarkers in Osteoporosis. BioMed Res. Int. 2016:11.

141. Tang P, Xiong Q, Ge W, Zhang L. (2014) The role of MicroRNAs in Osteoclasts and Osteoporosis. RNA Biol. 11:1355-63.

142. Chen C, et al. (2014) MiR-503 Regulates Osteoclastogenesis via Targeting RANK. J. Bone Miner. Res. 29:338-47.

143. Zhu R, Liu X, Zhu Y, He Z. (2016) MiRNAs: potential diagnostic and therapeutic targets for cerebral ischaemia. Neurol. Res. 38:86-92.

144. Devaux Y, et al. (2015) MicroRNAs: new biomarkers and therapeutic targets after cardiac arrest? Critical Care. 19:54.
145. Ryan BM, Robles AI, Harris CC. (2010) Genetic variation in microRNA networks: the implications for cancer research. Nat. Rev. Cancer. 10:389-402.

146. Basu A, et al. (2011) MicroRNA-375 and MicroRNA-221: Potential Noncoding RNAs Associated with Antiproliferative Activity of Benzyl Isothiocyanate in Pancreatic Cancer. Genes Cancer. 2:108-19.

147. Kloosterman WP, Lagendijk AK, Ketting RF, Moulton JD, Plasterk RHA. (2007) Targeted Inhibition of miRNA Maturation with Morpholinos Reveals a Role for miR-375 in Pancreatic Islet Development. PLoS Biol. 5: e203.

148. Hornung V, et al. (2005) Sequence-specific potent induction of IFN- $\alpha$ by short interfering RNA in plasmacytoid dendritic cells through TLR7. Nat. Med. 11:263-70.

149. Dalpke AH, Helm M. (2012) RNA mediated toll-like receptor stimulation in health and disease. RNA Biol. 9:828-42.

150. Sarvestani ST, et al. (2015) Sequence-dependent off-target inhibition of TLR7/8 sensing by synthetic microRNA inhibitors. Nucleic Acids Research. 43:1177-88.

151. Wu T-T, Zhou S-H. (2015) Nanoparticle-Based Targeted Therapeutics in Head-And-Neck Cancer. Int. J. Med. Sci. 12:187-200.

152. Pichiorri F, et al. (2008) MicroRNAs regulate critical genes associated with multiple myeloma pathogenesis. Proc. Nat. Acad. Sci. U.S.A. 105:12885-90.

153. Saki N, et al. (2015) Involvement of MicroRNA in T-Cell Differentiation and Malignancy. Int. J. Hematol. Oncol. Stem Cell Res. 9:33-49.

154. Miele E, et al. (2012) Nanoparticle-based delivery of small interfering RNA: challenges for cancer therapy. Int. J. Nanomed. 7:3637-57.

155. Baumann V, Winkler J. (2014) miRNA-based therapies: Strategies and delivery platforms for oligonucleotide and non-oligonucleotide agents. Future Med. Chem. 6:1967-84.

156. Chen Y, Gao D-Y, Huang L. (2015) In vivo delivery of miRNAs for cancer therapy: Challenges and strategies. Adv. Drug Del. Rev. 81:128-41.

157. Navarro G, Pan J, Torchilin VP. (2015) Micelle-like Nanoparticles as Carriers for DNA and siRNA. Mol. Pharm. 12:301-13.

158. Zhang $Y$, Wang Z, Gemeinhart RA. (2013) Progress in MicroRNA Delivery. J. Control. Release. 172:962-74.

159. Zhou J, Atsina K-B, Himes BT, Strohbehn GW, Saltzman WM. (2012) Novel Delivery Strategies for Glioblastoma. Cancer J. 18:10.1097.

160. Zheng D, et al. (2012) Topical delivery of siRNA-based spherical nucleic acid nanoparticle conjugates for gene regulation. Proc. Nat. Acad. Sci. U.S.A. 109:11975-80.

161. Villanueva MT. (2015) Tumorigenesis: miRNAs - novel regulators in skin cancer. Nat. Rev. Cancer. 15:5.

162. Sureban SM, et al. (2011) Nanoparticle-based delivery of siDCAMKL-1 increases microRNA-144 and inhibits colorectal cancer tumor growth via a Notch-1 dependent mechanism. J. Nanobiotechnol. 9:40.

163. Lennox KA, Behlke MA. (2011) Chemical modification and design of anti-miRNA oligonucleotides. Gene Ther. 18:1111-20.

164. Cheng CJ, Saltzman WM, Slack FJ. (2013) Canonical and Non-Canonical Barriers Facing AntimiR Cancer Therapeutics. Curr. Med. Chem. 20:3582-93.

165. Trang P, et al. (2011) Systemic Delivery of Tumor Suppressor microRNA Mimics Using a Neutral Lipid Emulsion Inhibits Lung Tumors in Mice. Mol. Ther. 19:1116-22.

166. Kumar S, Mapa K, Maiti S. (2014) Understanding the Effect of Locked Nucleic Acid and 2'-O-Methyl Modification on the Hybridization Thermodynamics of a miRNA-mRNA Pair in the Presence and Absence of AfPiwi Protein. Biochemistry. 53:1607-15.

167. Schneider MD, et al. (2006) Gawky is a component of cytoplasmic mRNA processing bodies required for early Drosophila development. J. Cell Biol. 174:349-58.

168. Squadrito Mario L, et al. (2014) Endogenous RNAs Modulate MicroRNA Sorting to Exosomes and Transfer to Acceptor Cells. Cell Reports. 8:1432-46.

169. Wang B, Ricardo S. (2014) Role of microRNA machinery in kidney fibrosis. Clin. Exp. Pharmacol. Physiol. 41:543-50.

170. Graveel CR, Calderone HM, Westerhuis JJ, Winn ME, Sempere LF. (2015) Critical analysis of the potential for microRNA biomarkers in breast cancer management. Breast Cancer. 7:59-79.

171. Lu J, et al. (2005) MicroRNA expression profiles classify human cancers. Nature. 435:834-38.

172. DeVos SL, Miller TM. (2013) Antisense Oligonucleotides: Treating Neurodegeneration at the Level of RNA. Neurotherapeutics. 10:486-97.

173. Thomson DW, Bracken CP, Goodall GJ. (2011) Experimental strategies for microRNA target identification. Nucleic Acids Res. 39:6845-53.

174. Laganà A, Shasha D, Croce CM. (2014) Synthetic RNAs for Gene Regulation: Design Principles and Computational Tools. Front. Bioeng. Biotechnol. 2:65.

175. Rivera Díaz M, Vivas-Mejia PE. (2013) Nanoparticles as Drug Delivery Systems in Cancer Medicine: Emphasis on RNAi-Containing Nanoliposomes. Pharmaceuticals. 6:1361-80.

Cite this article as: Bhadra U, Patra P, Chhatai J, Pal-Bhadra M. (2016) Pygmy MicroRNA: Surveillance cops in therapy kingdom. Mol. Med. 22:759-75. 